Article

\title{
Effects of Loaded End Distance and Moisture Content on the Behavior of Bolted Connections in Squared and Round Timber Subjected to Tension Parallel to the Grain
}

\author{
Antonin Lokaj ${ }^{1}\left(\mathbb{D}\right.$, Pavel Dobes ${ }^{1, *(1)}$ and Oldrich Sucharda ${ }^{2,3}(\mathbb{C}$ \\ 1 Department of Structures, Faculty of Civil Engineering, VSB-Technical University of Ostrava, \\ 70800 Ostrava-Poruba, Czech Republic; antonin.lokaj@vsb.cz \\ 2 Department of Building Materials and Diagnostics of Structures, Faculty of Civil Engineering, \\ VSB-Technical University of Ostrava, 70800 Ostrava-Poruba, Czech Republic; oldrich.sucharda@vsb.cz \\ 3 Centre of Building Experiments, Faculty of Civil Engineering, VSB-Technical University of Ostrava, \\ 70800 Ostrava-Poruba, Czech Republic \\ * Correspondence: pavel.dobes1@vsb.cz; Tel.: +42-059-732-1396
}

Received: 31 October 2020; Accepted: 29 November 2020; Published: 3 December 2020

\begin{abstract}
This article presents the results of static tests on bolted connections in squared and round timber with inserted steel plates. The experiment evaluates structural timber connections with different distances between the fastener and the loaded end at different moisture contents. Specimens were loaded by tension parallel to the grain and load-deformation diagrams were recorded. Fifty-six specimens with three different distances between the fastener and the loaded end, at different moisture contents, were tested. The results were statistically evaluated using regression analysis, complemented with load-deformation curves, and compared with calculations according to the valid standard for design of timber structures. A decrease in the evaluated load-carrying capacity with increasing moisture content was confirmed experimentally. A slight increase in the evaluated load-carrying capacity with increasing fastener distance from the loaded end was found.
\end{abstract}

Keywords: connection; timber; test; bolt; steel plate; moisture content; failure

\section{Introduction}

Currently, the use of timber as a building material is becoming increasingly popular. The general trend of using natural, renewable and easily recyclable materials in construction practice contributes to this fact. Increasingly, environmental requirements and long-term sustainability in construction are gaining prominence and application (e.g., in buildings [1], bridges and footbridges [2]). Timber structures, which are commonly used as a substitute for steel and concrete structures, considerably mitigate the impact on the environment thanks to their smaller carbon footprint [3].

One of the most important areas in the design of timber structures is connections [4-6]. Connections affect the overall composition of the load-carrying structure and dimensions of the main load-carrying members [7]. The load-carrying capacity and the stiffness of connections are crucial to the serviceability and durability of the whole structure, especially for large-span structures with many connections $[1,7]$ and structures with heavily loaded connections [2]. The most common types of connections in timber structures use metal mechanical fasteners, which are often used in combination with steel plates slotted into cut-outs in timber members (see Figure 1) [8-16].

The stiffness of connections is closely related to the physical and mechanical properties of timber and fasteners $[17,18]$, as well as to the design of individual details (i.e., placement of individual 
fasteners and the whole connection geometry) [19-21]. The influence of connection stiffness manifests in increased deformations and redistribution of internal forces, which can significantly affect the static design of the whole load-carrying structure [7].

One of the most important physical property of timber that significantly affects its strength and deformation properties [13,22], and its durability especially [23], is the moisture content. Due to atmospheric influences, timber, as a hygroscopic material, constantly exchanges moisture with the surrounding environment [24,25]. The effects of moisture content on the load-carrying capacity and stiffness of connections has been proven in long-term research by forest researchers in the US [26]. Fluctuations in moisture content also result in volume changes (shrinkage and swelling), which, due to the formation of cracks and reduction in embedment strength, negatively affects the load-carrying capacity of connections [25]. As a result, it is necessary to consider the influence of the environmental conditions (especially humidity) under which the structure will be built, as well as the type of load that will be carried. The hygroscopic properties of timber can be improved, for example, by temperature treatment [24].

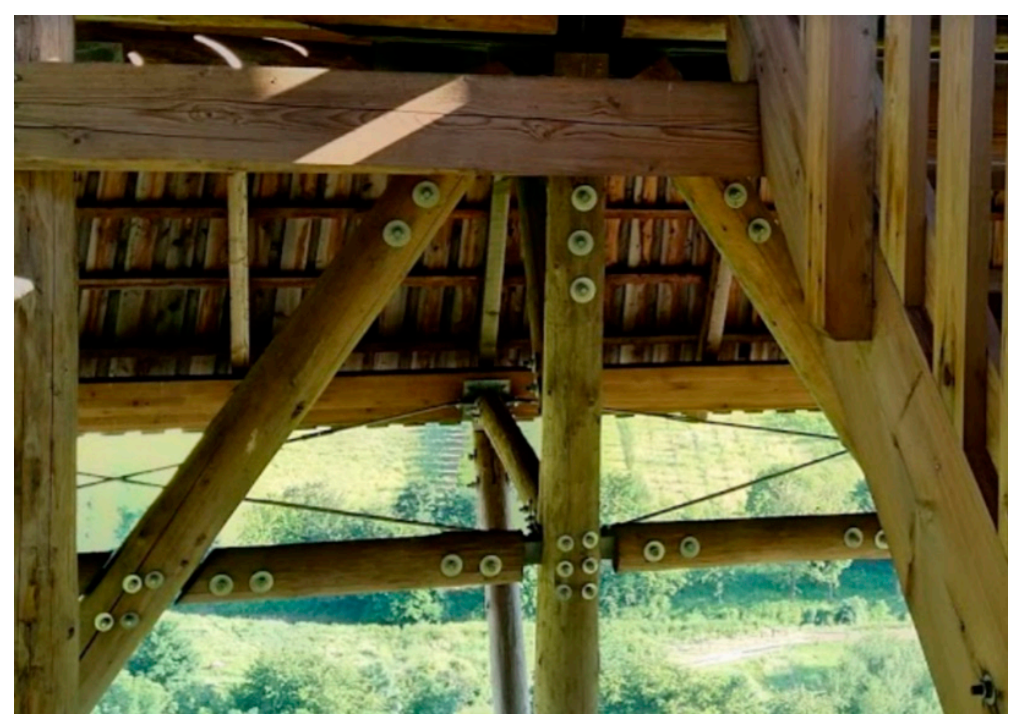

Figure 1. Practical use of connections in timber structures with mechanical fasteners and steel plates.

The contemporary European standard for the design of timber structures EN 1995-1 (Eurocode 5) [27] includes calculations for timber-to-timber or steel-to-timber connections using mechanical fasteners such as bolts, dowels, nails, screws, etc. Timber-to-timber connections also include combinations of different timber materials [28]. Calculations of load-carrying capacity and connection stiffness do not take into account the edge and end distances nor spacings for fasteners; they are only given as the minimum standard requirement to prevent brittle failure $[19,29,30]$. Rahim et al. investigated the influence of double-shear steel-to-timber connection geometry (different spacings, end distances) on the initial stiffness [20]. It was found that the initial stiffness can be affected by many factors that are not taken into account in Eurocode 5. Awaludin and Saputro pointed to the possibility of using values smaller than those recommended for the distance between the fastener and the loaded end for a dowel-type connection in laminated veneer lumber [21].

Eurocode 5 and current design codes in many other countries are not optimal, although they are conservative [31]. The European standard only describes three modes, which do not represent total connection failure. Those failure modes are based on the so-called European yield model according to Johansen's theory from 1949 [32], which represents ductile failure modes. The main objective under this model is to design connections for which ductile failure comes before brittle failure, i.e. to design connections with the highest possible deformation capacity to prevent an unexpected collapse [33]. 
This approach is supported by several scientific studies $[19,29,34]$. Various connection reinforcement methods have also been used to prevent brittle splitting [12,14,35].

Current research indicates a disagreement between experiments (brittle failure) and design standards (ductile failure) [30,31]. Real total failure of bolted connections occurs due to tension or shear stress [36] and in some cases (multiple shear connections with several slotted-in steel plates) may even be crucial [16]. Brittle failure modes of steel-to-timber bolted connections loaded by tension parallel to the grain were described in [34]. Jorissen developed a new design approach based on fracture mechanics [29].

In this study, static tests were performed on bolted connections in squared and round timber specimens with inserted steel plates. Several connection variants with different distances between the fastener and the loaded end and with different moisture contents (square timber only) were chosen in order to verify if the real load-carrying capacity was influenced by distance. The specimens were subjected to tension parallel to the grain, until the connections failed.

\section{Research Significance}

Determining the load-carrying capacity of connections in timber structures and applying new knowledge to the European standard for timber structures design [27] are areas which are still under development. This research describes and compares the behavior of connections in squared and round timber, loaded in tension parallel to the grain, with different distances between the fastener and the loaded end and for different moisture contents.

Some studies from the scientific literature have investigated the design and behavior of dowel-type connections in timber structures, mainly based on experimental research. For example, important findings can be found in publications [4-6]. The relevance of this issue is also evidenced by the number of research papers written by authors mentioned in this paper.

The aim of this study is also to build on previous research activities conducted at the Faculty of Civil Engineering of the VSB Technical University of Ostrava by Klajmonova et al. A series of experiments was carried out to compare the load-carrying capacity of bolted connections with inserted steel plates, both for squared timber and round timber, but always for the same placement and number of fasteners [8-11]. Methods of effective reinforcement for bolted connections subjected to brittle failure were also designed and tested [12].

Some important new findings from our experimental testing have already been published and discussed at international conferences $[37,38]$ and should be further extended.

Finally, the influence of moisture content on the behavior of a similar type of connection (bolt M12, glued laminated timber) loaded parallel to the grain has recently been investigated [13].

\section{Design and Analysis of Timber Structure Connections in Europe}

In most European countries, according to the current legislation, timber structures are designed and constructed based on Eurocode 5 [27]. Selected important knowledge about connections in timber structures is described in this chapter (for more detailed information, see the EN 1995-1 standard).

The geometric arrangement of fasteners in a connection (spacings, edge and end distances) has to meet minimum values to achieve the expected strength and stiffness. The most important value is the end distance from the loaded end (designation $a_{3, t}$ according to the standard). The minimum value depends on the fastener diameter $d$ and is given according to Equation (1).

$$
a_{3, \mathrm{t}}=\max (7 d ; 80 \mathrm{~mm})
$$

When determining the characteristic load-carrying capacity of connections with dowel-type fasteners made of metal, it is necessary to take into account the embedment strength of the timber, the yield strength of the fastener and less commonly the withdrawal strength of the fastener. 
Connections are distinguished based on the type of materials to be connected. There are timberto-timber, panel-to-timber and steel-to-timber connections.

For a double shear steel-to-timber connection with a steel plate of any thickness as the central member, the characteristic load-carrying capacity of one fastener for a single shear plane is determined as the minimum value according to Equation (2) for the failure modes shown in Figure 2 (failure mode $a$ represents embedment of the timber, failure mode $b$ represents bending of the fastener and failure mode $c$ is the combination of both mentioned failure modes) or in [27]. The first member in the formula is the load-carrying capacity based on the Johansen yield theory [32] and the second member represents the so-called rope effect $[39,40]$, which in Eurocode 5 has to be limited to $25 \%$ of the Johansen part for bolts. If the contribution from the rope effect is unknown, then it is taken as zero.

$$
F_{v, R k}=\left\{\begin{array}{c}
f_{h, 1,1, \cdot t_{1} \cdot d} \\
f_{h, 1, k} \cdot t_{1} \cdot d \cdot\left[\sqrt{2+\frac{4 \cdot M_{y, R k}}{f_{h, 1, k} \cdot d \cdot t_{1}^{2}}}-1\right]+\frac{F_{a x, R k}}{4} \\
2.3 \cdot \sqrt{M_{y, R k} \cdot f_{h, 1, k} \cdot d}+\frac{F_{a x, R k}}{4}
\end{array}\right.
$$

here,

$F_{v, R k}$ is the characteristic load-carrying capacity for a single shear per fastener [N];

$f_{h, k}$ is the characteristic embedment strength in the timber member $\left[\mathrm{N} / \mathrm{mm}^{2}\right]$;

$t_{1}$ is the smaller of the thicknesses of the timber side member [mm];

$d$ is the diameter of the fastener [mm];

$M_{y, R k}$ is the characteristic yield moment of the fastener [N/mm];

$F_{a x, R k}$ is the characteristic withdrawal capacity of the fastener [N].

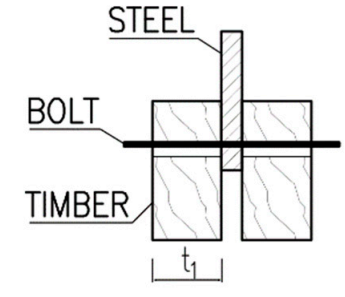

(a)

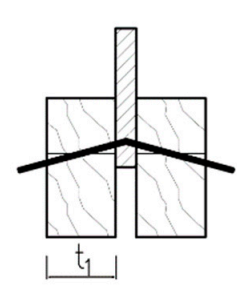

(b)

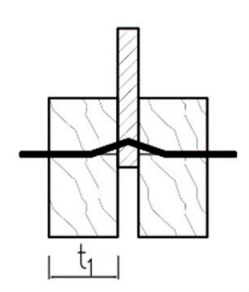

(c)

Figure 2. Failure modes for steel-to-timber connections: (a) Embedment of the timber; (b) Bending of the fastener; (c) Combination of both failures.

For bolts, the characteristic value of the yield moment depends on the bolt diameter $d$ and the characteristic tensile strength $f_{u, k}$ and is determined according to Equation (3).

$$
M_{y, R k}=0.3 \cdot f_{u, k} \cdot d^{2.6}
$$

For bolts, the characteristic embedment strength value in timber parallel to the grain depends on the bolt diameter $d$ and the characteristic density of timber $\rho_{k}$ and should be calculated according to Equation (4).

$$
f_{h, 0, k}=0.082 \cdot(1-0.01 \cdot d) \cdot \rho_{k}
$$

Moisture content is given by the ratio of water weight to dry weight. When stored in air, European spruce timber dries to the so-called hygroscopic equilibrium moisture content (around 20\%). The ideal moisture content for spruce timber used in exterior construction is considered to be $12 \%$ [2].

The effect of moisture on the mechanical properties of timber is significant. As the moisture content increases, the strength and stiffness of the timber decrease. The linear relationship between mechanical properties and moisture content can be considered to be in the range of $8 \%$ to $20 \%$ for moisture content [26]. 
When determining design values of mechanical properties according to [27], the influence of air humidity can be taken into account by assigning the structure to one of the three service classes, which affects the choice of the relevant modification factor $k_{\text {mod }}$ and deformation factor $k_{d e f}$.

\section{Methodology of Testing}

\subsection{Description of Materials for Test Specimens}

For tension tests parallel to the grain, specimens were made of squared timber with cross-sectional dimensions of $60 \times 120 \mathrm{~mm}$ and round timber with a diameter of $60 \mathrm{~mm}$. All specimens consisted of two equal parts due to easier production of final specimens (placement of steel plates between individual parts). The specimens were made of spruce timber of the C24 strength class (determined on the basis of the standard [41]). Specimens of three different lengths were tested (see Figures 3 and 4): $400 \mathrm{~mm}$ (designation $\mathrm{H} 1$ and K1), $480 \mathrm{~mm}$ (designation H2 and K2) and $560 \mathrm{~mm}$ (designation $\mathrm{H} 3$ and K3). The circular holes for placing fasteners had a diameter of $20 \mathrm{~mm}$.

High tensile bolts, grade $8.8\left(f_{y}=640 \mathrm{MPa}, f_{u}=800 \mathrm{MPa}\right)$ with a diameter of $20 \mathrm{~mm}$, were used as fasteners. The bolts were placed at three different distances from the loaded end: $140 \mathrm{~mm}(=7 \times$ bolt diameter), $180 \mathrm{~mm}(=9 \times$ bolt diameter $)$ and $220 \mathrm{~mm}(=11 \times$ bolt diameter). The axial spacing between two bolts in one specimen was $120 \mathrm{~mm}$.

The steel plates (see Figure 5) were made of structural-grade steel S235J0; their thickness was $10 \mathrm{~mm}$. The dimensions of the steel plates also varied depending on the distance between the fastener and the loaded end. The protruding part of the plates needed for clamping specimens into the jaws of the testing machine was $180 \mathrm{~mm}$ long (see Figure 6). The plates were provided with circular holes with a diameter of $22 \mathrm{~mm}$ for placing bolts (a clearance of $2 \mathrm{~mm}$ was left).

For detailed specifications of dimensions, see Figures 3 and 5 and Table 1.
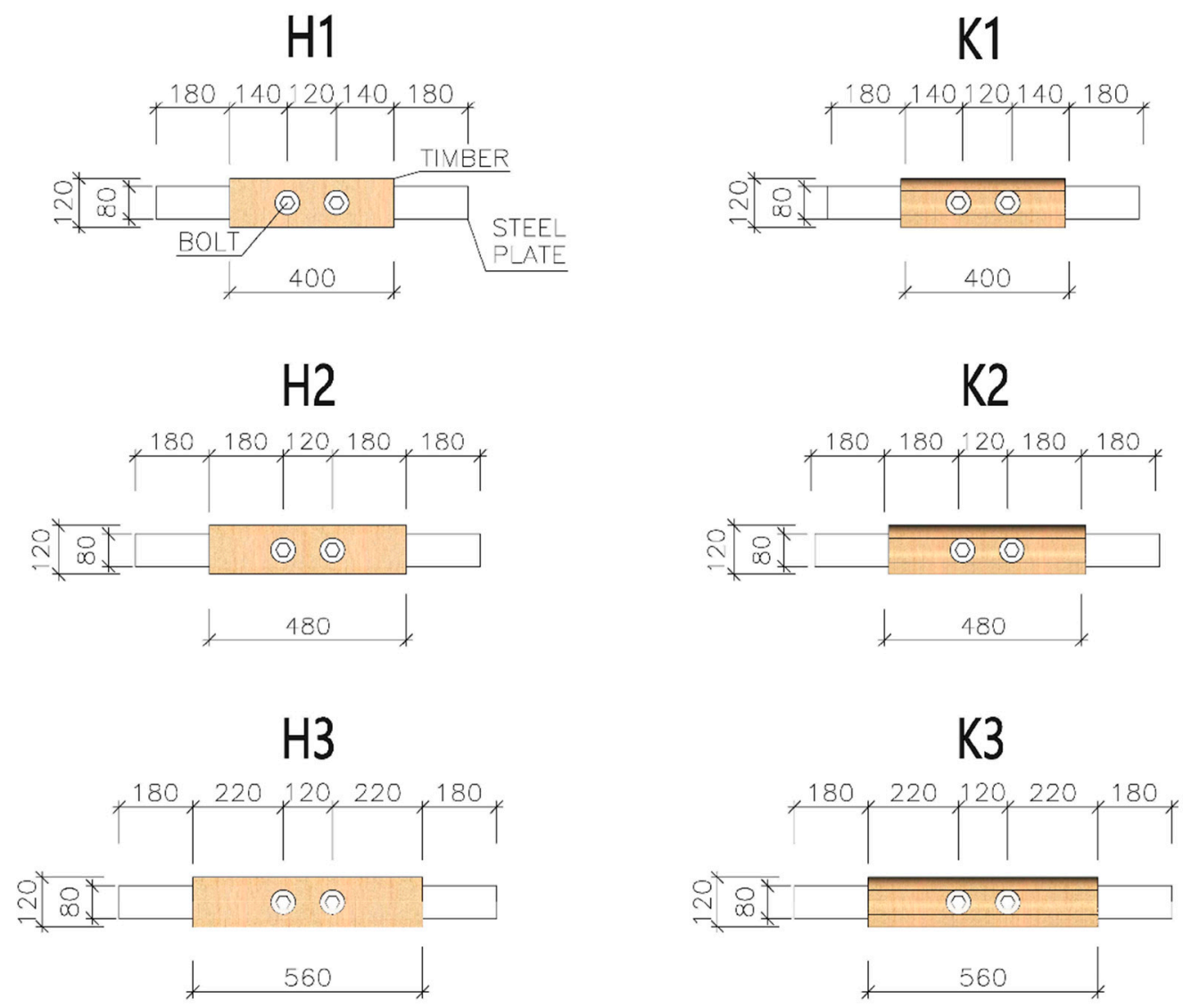

Figure 3. Types of specimens for tension tests parallel to the grain. 


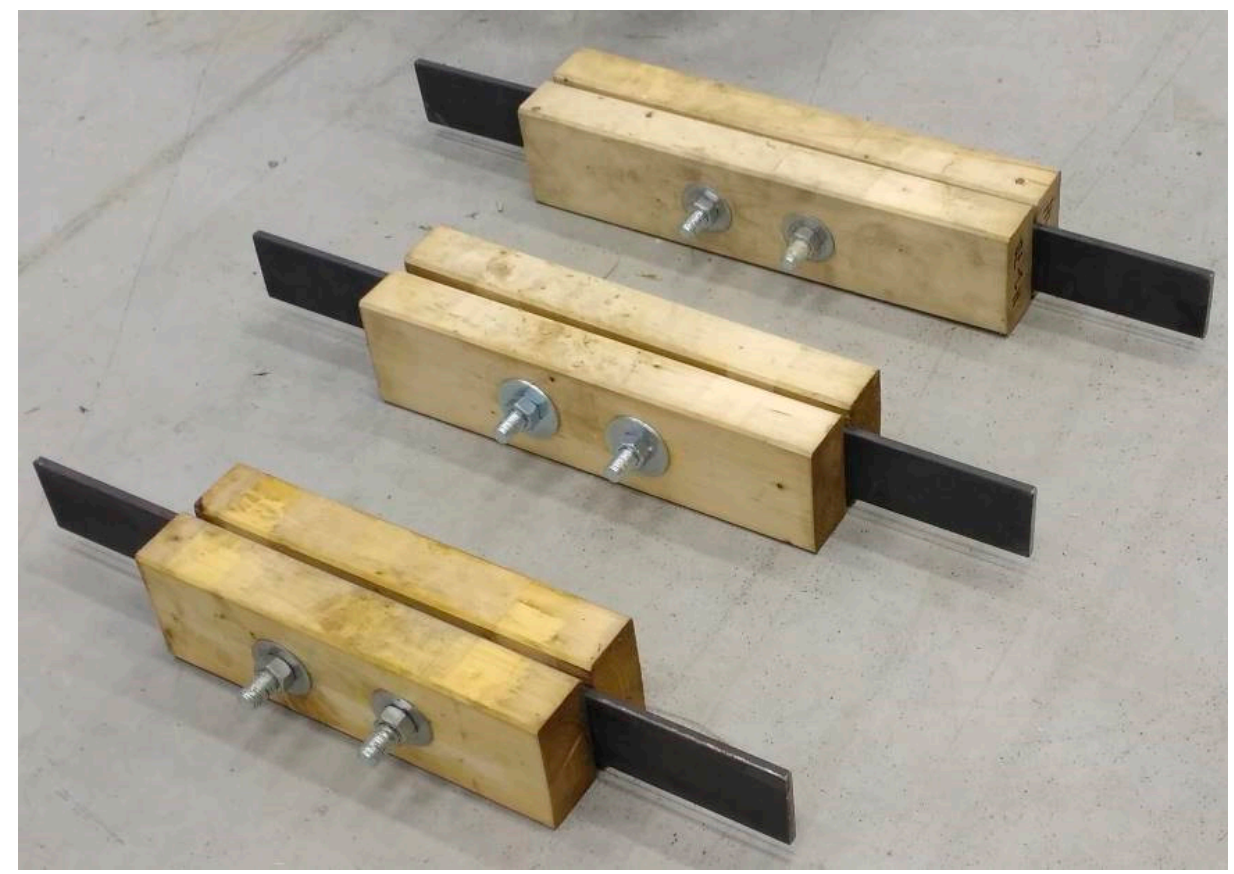

Figure 4. All types of squared specimens before testing.

P10 $80 \times 370$ with a hole $\varnothing 22 \mathrm{~mm}$ for bolt M20 8.8

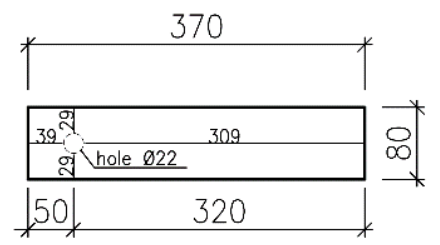

P10 $80 \times 410$ with a hole $\varnothing 22 \mathrm{~mm}$ for bolt M20 8.8

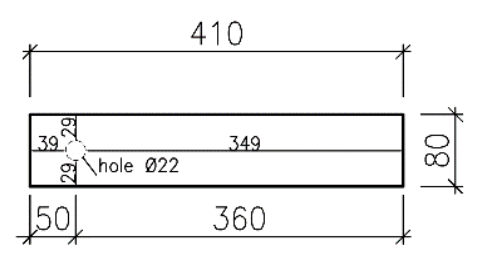

P10 80x450 with a hole $\varnothing 22 \mathrm{~mm}$ for bolt M20 8.8

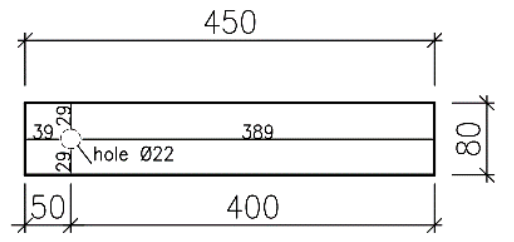

Figure 5. Dimensions of steel plates for tension tests parallel to the grain.

All timber specimens were produced and industrially manufactured at approximately equilibrium moisture content (about $12 \%$ ). Some squared timber specimens were then moistened. The aim of this was not to achieve an accurate level of moisture in the tested timber, but to simulate adverse 
conditions that could occur during the service life of an actual supporting structure using these types of elements and connections. The specimens were exposed to changing atmospheric influences for six months (February-July) without sunlight. Some were protected against rainwater penetration inside (this corresponds to specimens with a moisture content between approximately $18 \%$ and $22 \%$ ). Some were not protected (this corresponds to specimens with a moisture content of about $30 \%$ and higher).

Table 1. Dimensions of all specimen types for tension tests parallel to the grain.

\begin{tabular}{ccccccc}
\hline Type of Specimen & H1 & H2 & H3 & K1 & K2 & K3 \\
\hline Number of specimens [-] & 15 & 13 & 13 & 5 & 5 & 5 \\
Length of timber specimen [mm] & 400 & 480 & 560 & 400 & 480 & 560 \\
Height of timber specimen [mm] & & $2 \times 60$ & & & $2 \times 60$ & \\
Width/diameter of timber & & 120 & & & $\varnothing 120$ & \\
$\quad$ specimen [mm] & 140 & 180 & 220 & 140 & 180 & 220 \\
Loaded end distance [mm] & 320 & 360 & 400 & 320 & 360 & 400 \\
Length of steel plate [mm] & & & & 10 & & \\
Thickness of steel plate [mm] & & & & & & \\
Width of steel plate [mm] & & & & & & \\
Diameter of fastener [mm] & & &
\end{tabular}

\subsection{Description of the Testing Course}

Several non-destructive tests were carried out before the main test to determine the quality of timber material, its moisture content and its density. The test specimens were weighed on a laboratory scale and their dimensions and moisture content were measured. Based on these data, the bulk density of the specimens and the density derived therefrom were determined according to [42,43]. Moisture content was measured using a capacitive material moisture meter according to [44].

The experiments were performed using the LabTest 6.1200 electromechanical testing machine (LABORTECH s.r.o., Opava, Czech Republic) with 1200 kN maximum electrohydraulic cylinder force (see Figure 6). The machine and testing procedure were controlled by computer software.

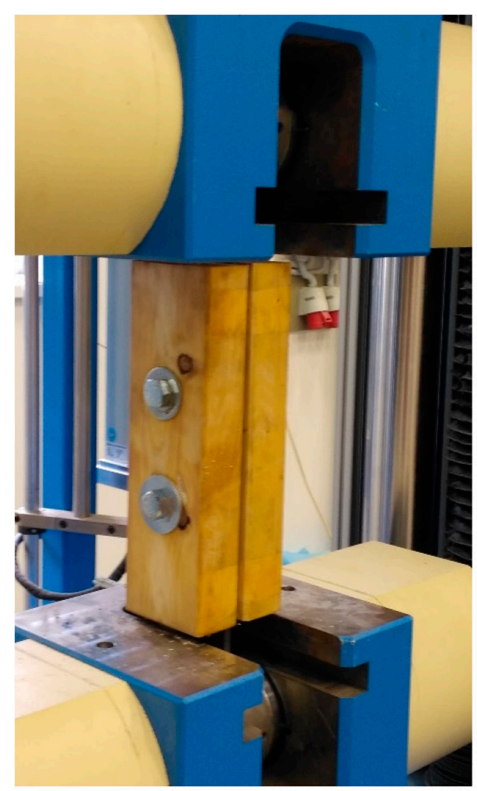

(a)

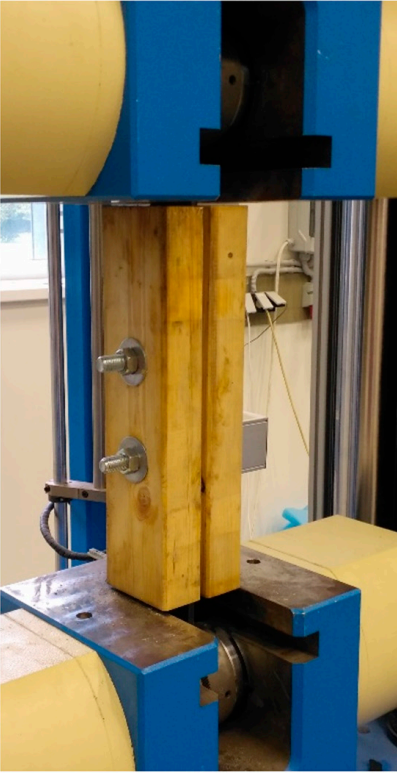

(b)

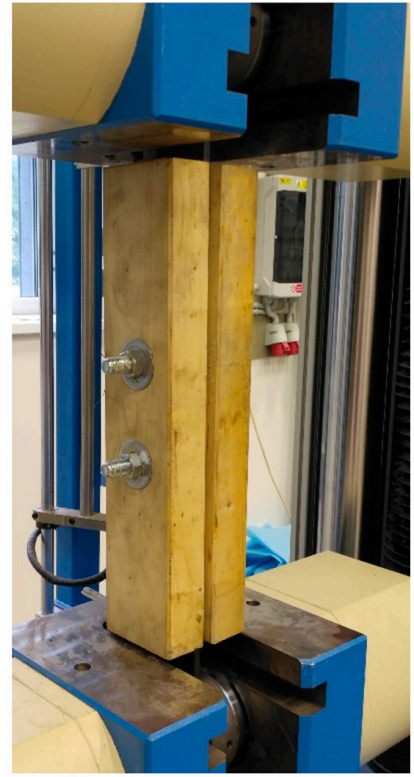

(c)

Figure 6. Specimens of squared timber clamped in the jaws of the testing machine: (a) H1 specimenlength $400 \mathrm{~mm}$; (b) H2 specimen-length $480 \mathrm{~mm}$; (c) H3 specimen-length $560 \mathrm{~mm}$.

The specimens were clamped into jaws with special serrations for better adhesion, so the slip in the jaws was eliminated. The lower jaw was static, the upper jaw was movable. The tested connections 
were subjected to an axial tensile load with possible additional effects from imperfections for which no significant effect on the evaluated parameters was expected. Possible imperfections included only geometric inaccuracies in cutting and drilling of the timber specimens. The arrangement and loading of the test specimens were designed to correspond to the actual state of connections in real supporting structures. The aim was not to simulate ideal conditions but to verify the behavior of the connections under realistic conditions.

For this reason, the bolts were also tightened by hand, using a spanner without specific tightening force, to eliminate the rope effect [39]. The tensile load was generated by electrohydraulic cylinders with a capacity of $1200 \mathrm{kN}$. During the test, the time, tensile force and deformations of the connection in the longitudinal direction (i.e., cross-head displacement) were continuously recorded. The loading course (see Figure 7) was carried out in accordance with the standard for testing the connections in timber structures with mechanical fasteners [45]. The following loading procedure was prescribed:

1. estimate the maximum force $F_{e s t}$, for the tested connection based on experience, calculation or pre-tests;

2. load the specimen to $40 \%$ of the estimated maximum force, $0.4 \cdot F_{\text {est }}$, then hold for $30 \mathrm{~s}$;

3. decrease the load to $10 \%$ of the estimated maximum force, $0.1 \cdot F_{\text {est }}$, then hold for $30 \mathrm{~s}$;

4. continue loading until the specimen fails.

A constant loading speed was chosen $(20 \mathrm{kN} / \mathrm{min})$. The total testing time for one specimen was about 10 to 15 min until failure (see Figure 8).

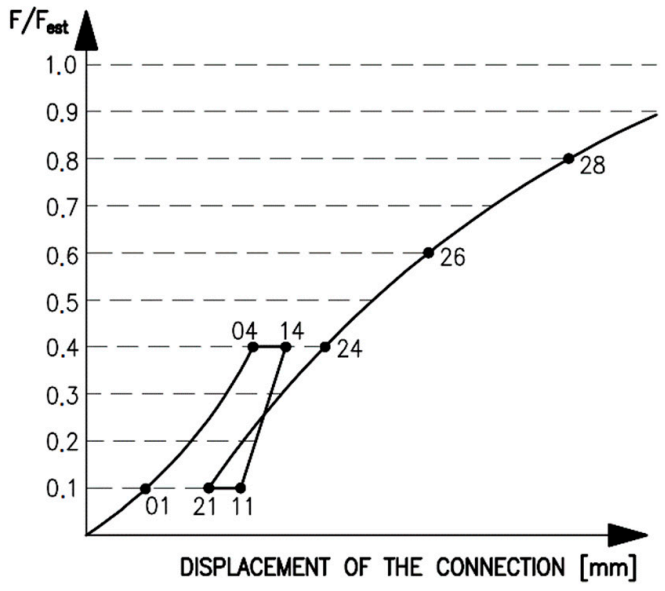

(a)

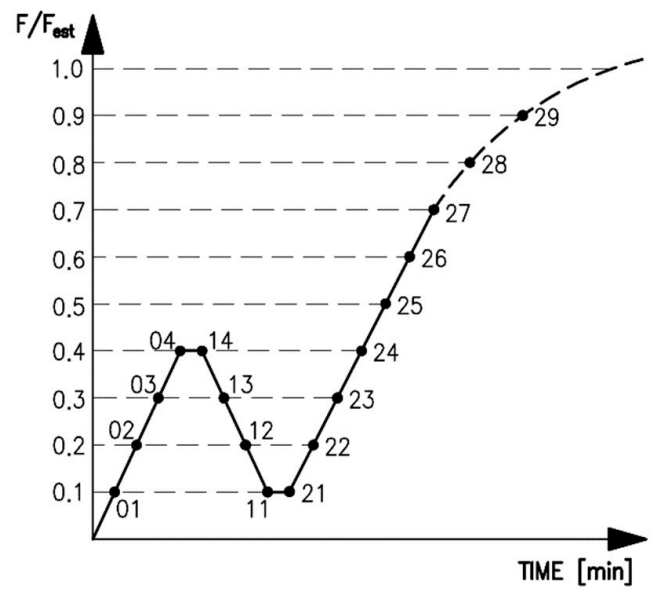

(b)

Figure 7. (a) Idealized load-displacement diagram and measured values; (b) The course of testing during time.

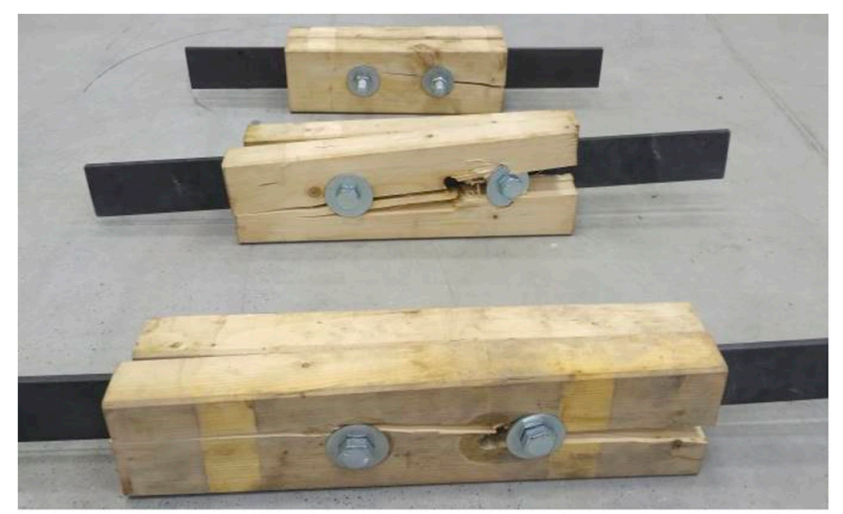

(a)

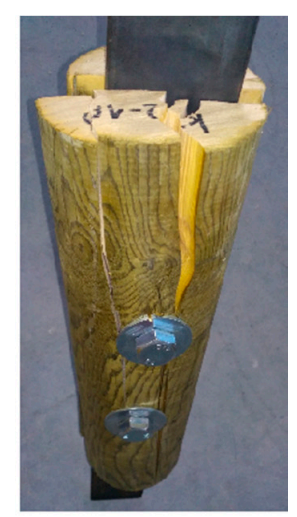

(b)

Figure 8. Specimens after failure: (a) Squared timber; (b) Round timber. 


\subsection{Evaluation of the Testing}

The measured displacements $v_{01}, v_{04}, v_{14}, v_{11}, v_{21}, v_{24}, v_{26}, v_{28}$ and the displacements at the maximum load were recorded. Based on the recorded data, it is possible to determine the initial displacement $v_{i}=v_{04}$, the modified initial displacement (Equation (5)), the permanent initial displacement (Equation (6)) derived therefrom and the initial slip modulus (Equation (7)) and the slip modulus (Equation (8)) derived therefrom [45].

$$
\begin{aligned}
v_{i, \text { mod }} & =\frac{4}{3} \cdot\left(v_{04}-v_{01}\right) \\
v_{s} & =v_{i}-v_{i, \bmod } \\
k_{i} & =0.4 \cdot \frac{F_{\text {est }}}{v_{i}} \\
k_{s} & =0.4 \cdot \frac{F_{\text {est }}}{v_{i, \text { mod }}}
\end{aligned}
$$

\section{Results}

For this work, six types of bolted connections in squared timber and round timber with inserted steel plates were tested. Only squared timber specimens were tested with different levels of moisture content. In total, fifty-six specimens were tested.

Figures 9-14 show the load-deformation curves of selected H1, H2, H3, K1, K2 and K3 specimens. In the graphs the initial loading at $40 \%$ of the estimated maximum force, the subsequent unloading to $10 \%$ of the estimated maximum force and the loading to failure can be seen. It is also possible to see the actual maximum force and the corresponding deformation at failure. The legends in the graphs for squared timber also contain information about the moisture content of the individual specimens.

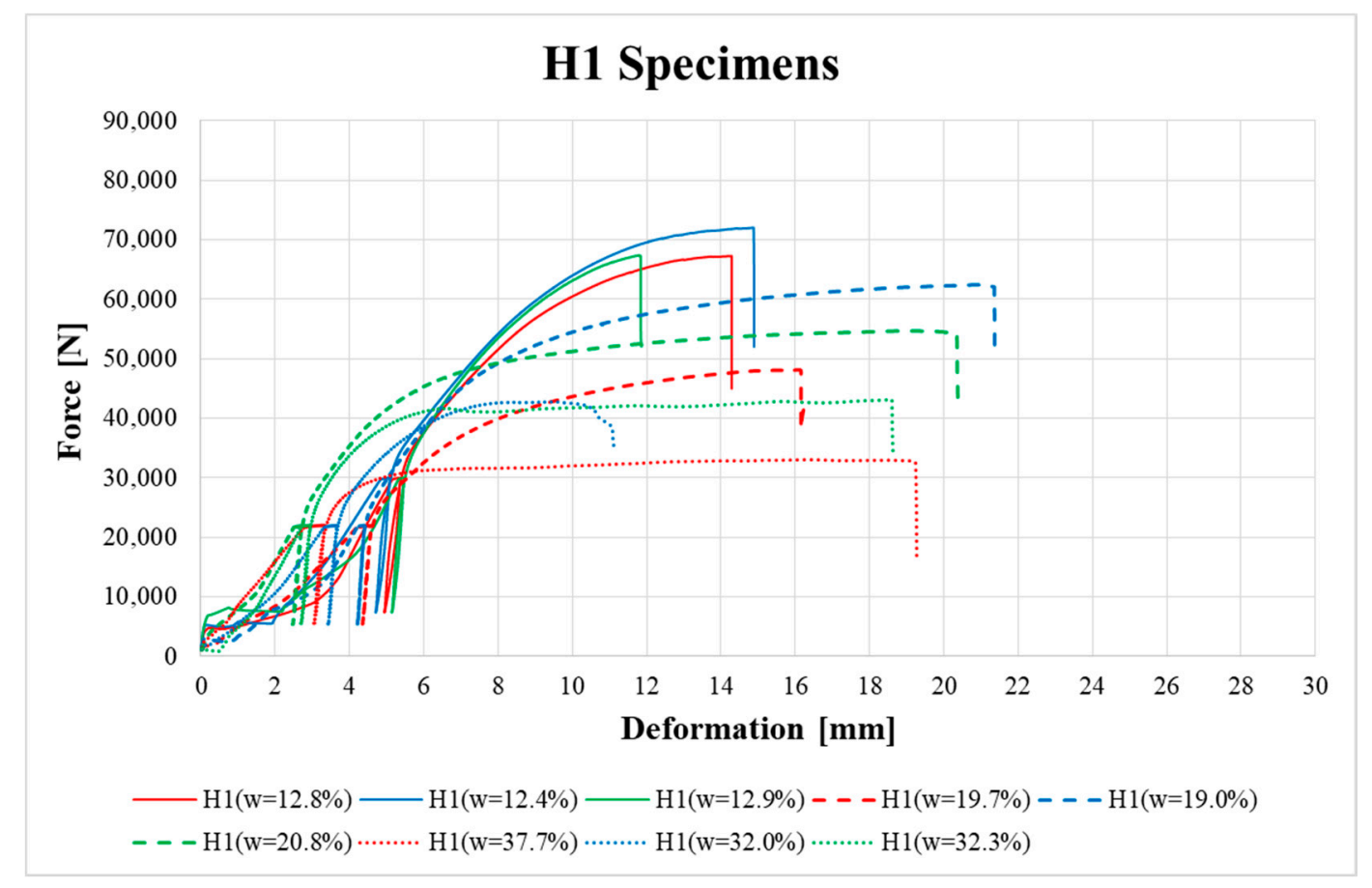

Figure 9. Load-deformation curves of $\mathrm{H} 1$ specimens. 


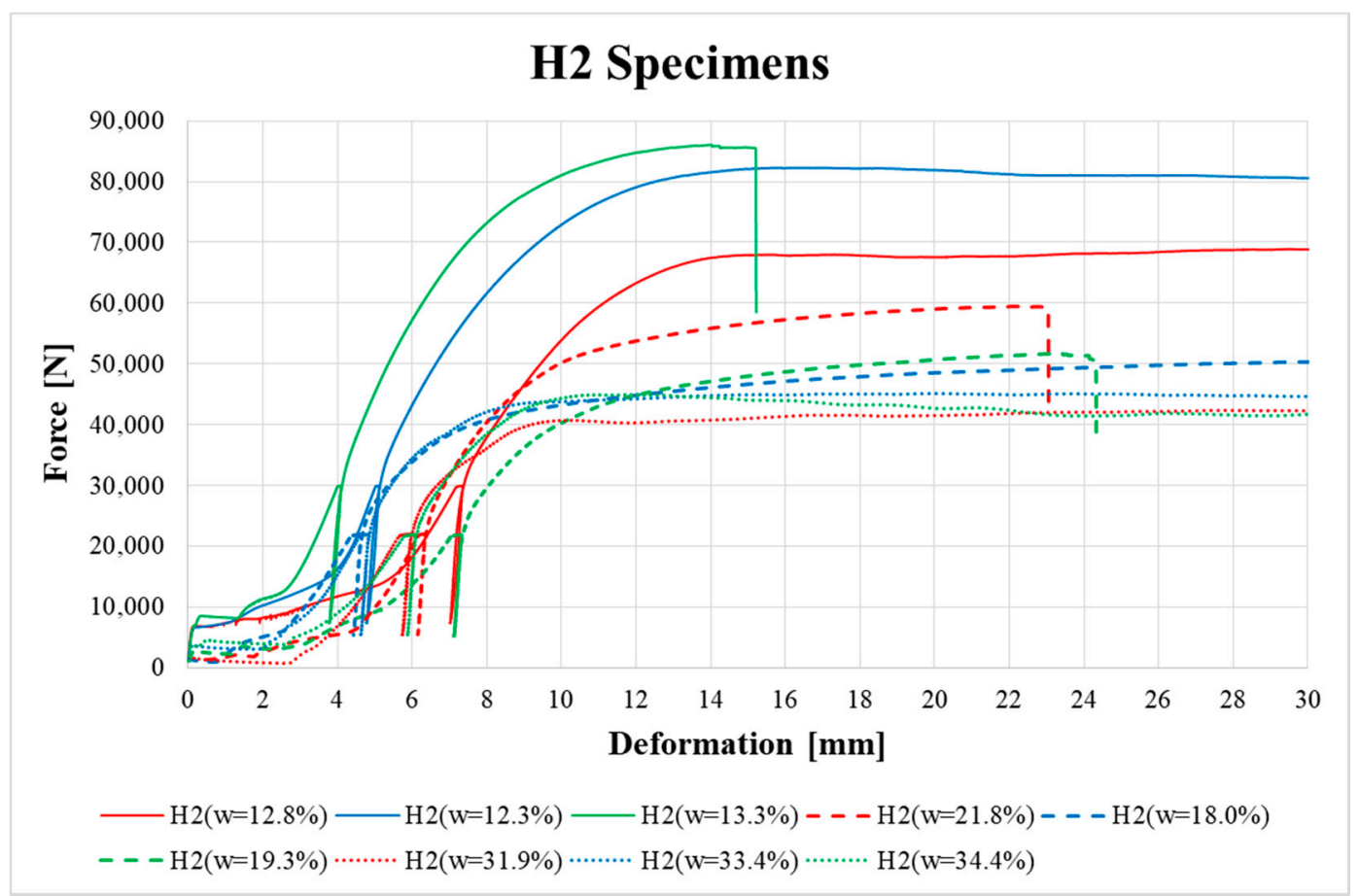

Figure 10. Load-deformation curves of H2 specimens.

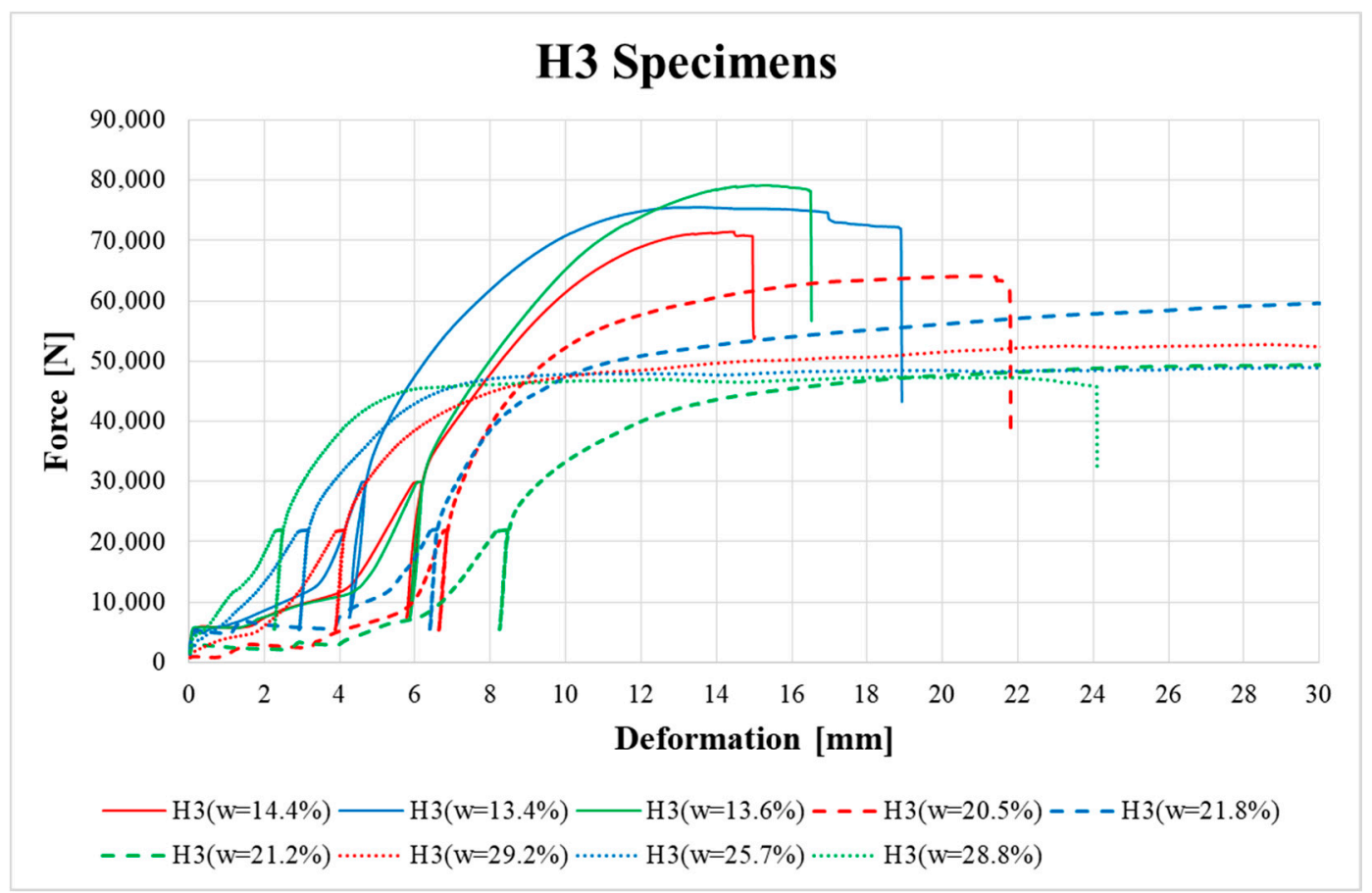

Figure 11. Load-deformation curves of H3 specimens. 


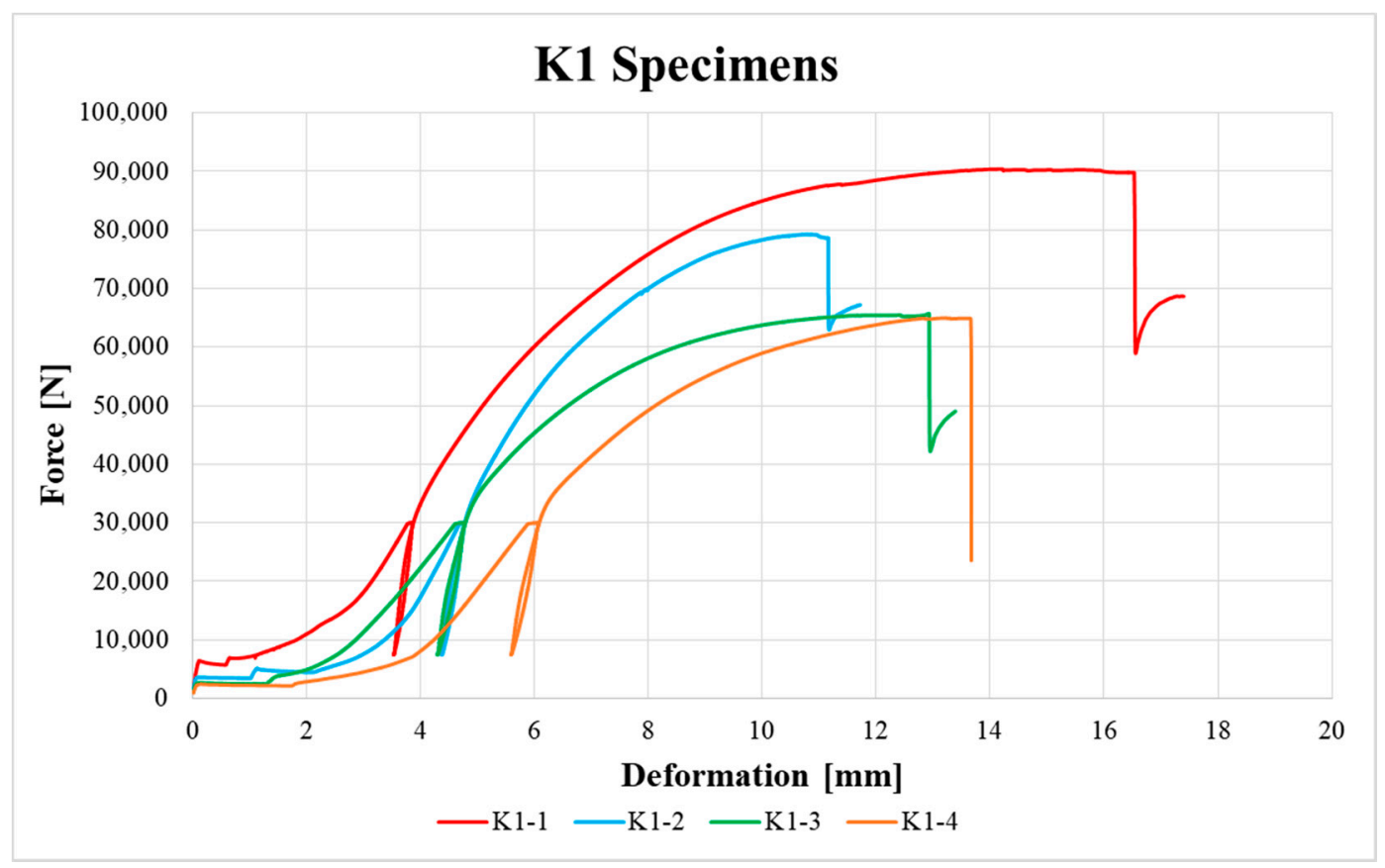

Figure 12. Load-deformation curves of K1 specimens.

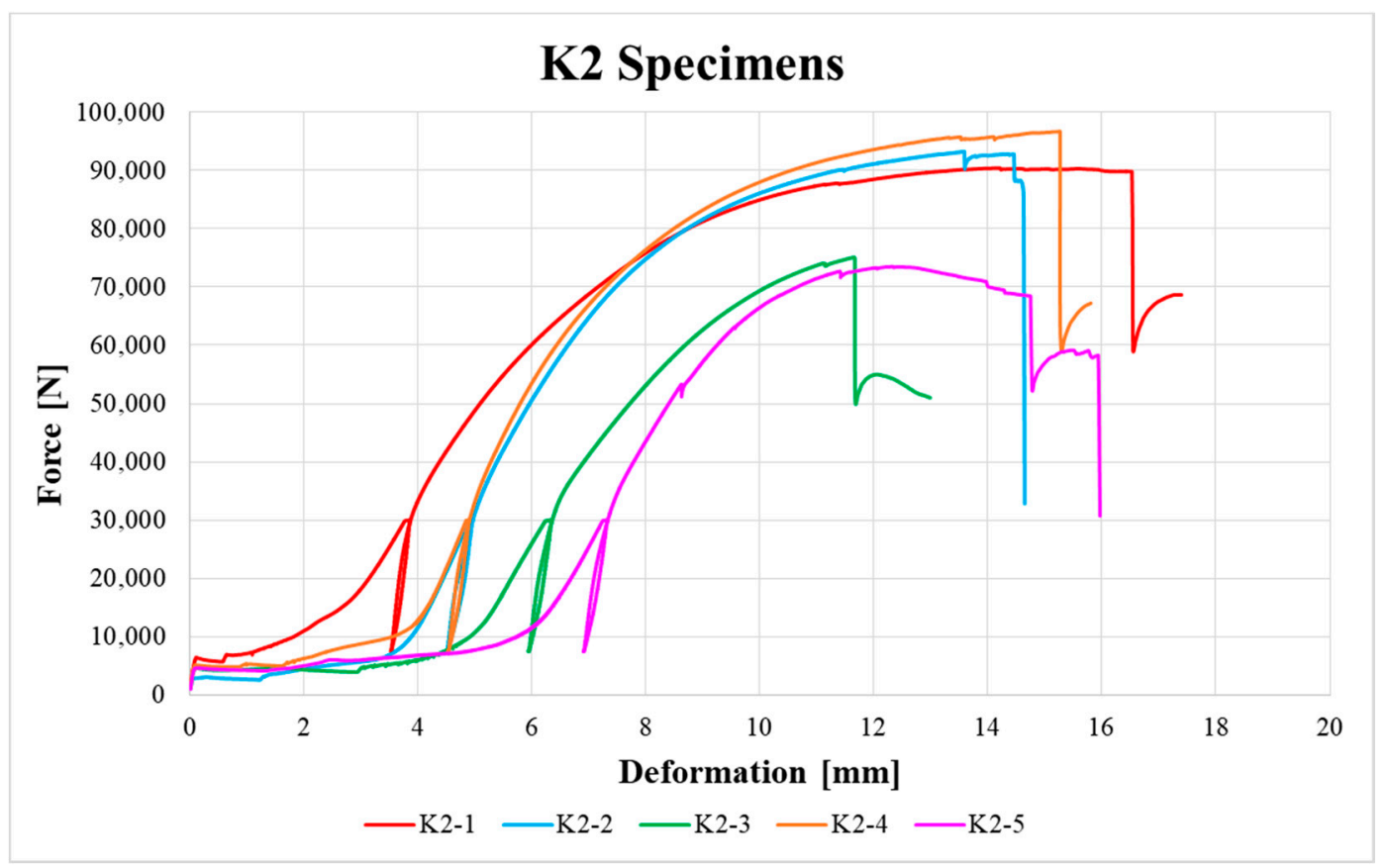

Figure 13. Load-deformation curves of K2 specimens. 


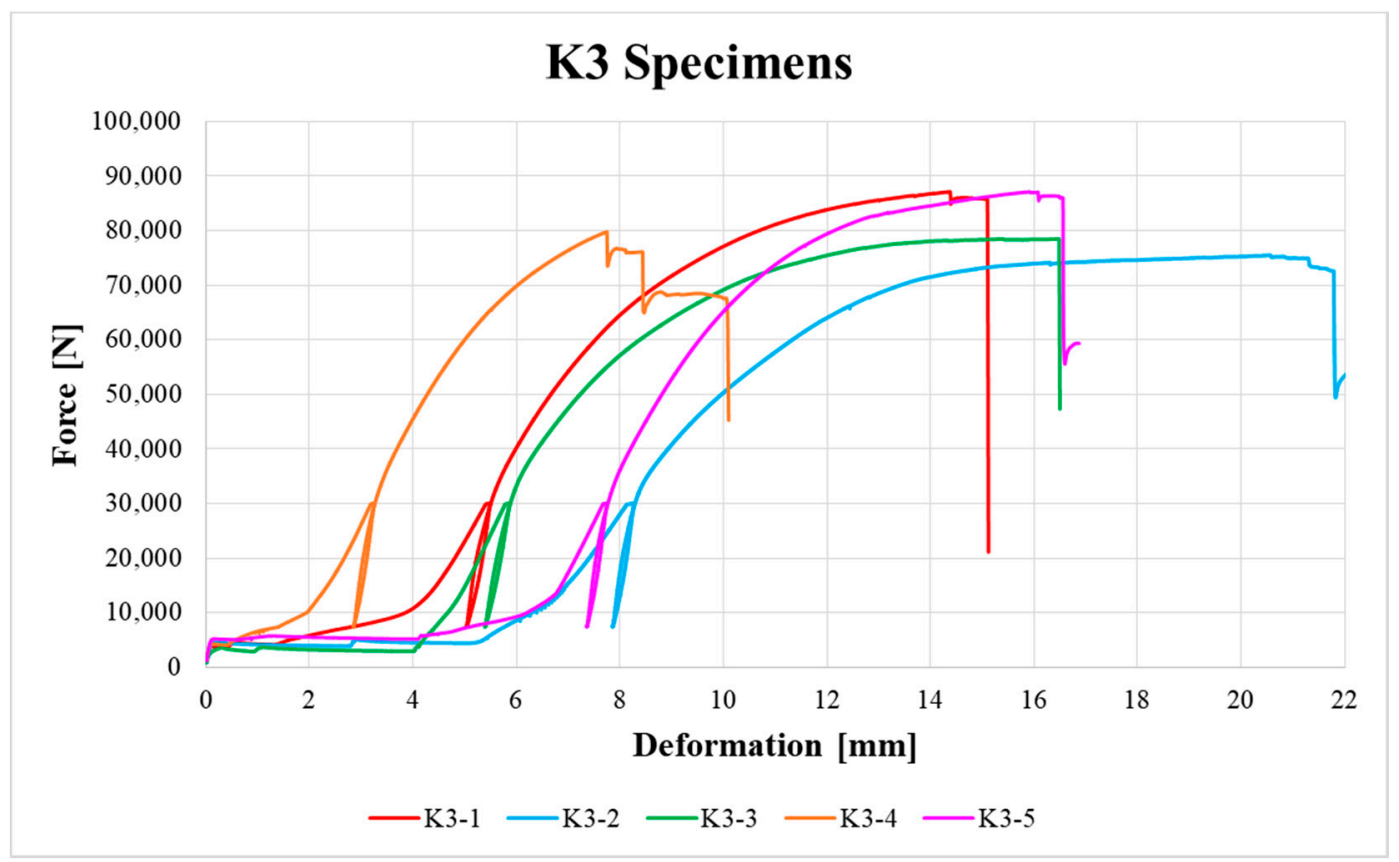

Figure 14. Load-deformation curves of K3 specimens.

Figures 15 and 16 show the probability density function and the variance in load-carrying capacity of squared timber and round timber specimens with an equilibrium moisture content of about $12 \%$. The statistical evaluation uses a normal distribution with input parameters, which were evaluated from the results of the experiment (see the average value and standard deviation in Table 2).

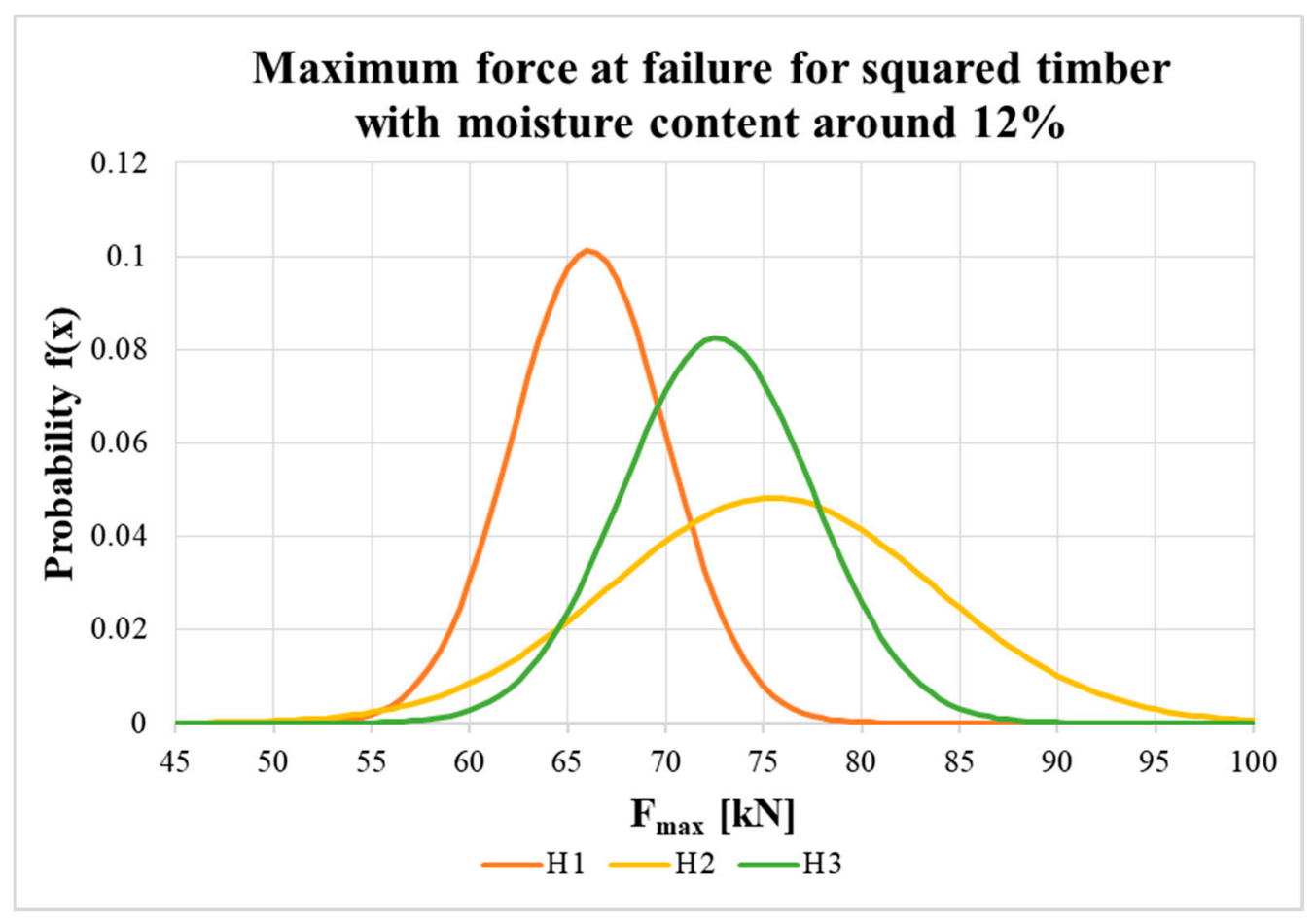

Figure 15. Probability density function of maximum force at failure for $\mathrm{H} 1, \mathrm{H} 2$ and $\mathrm{H} 3$. 


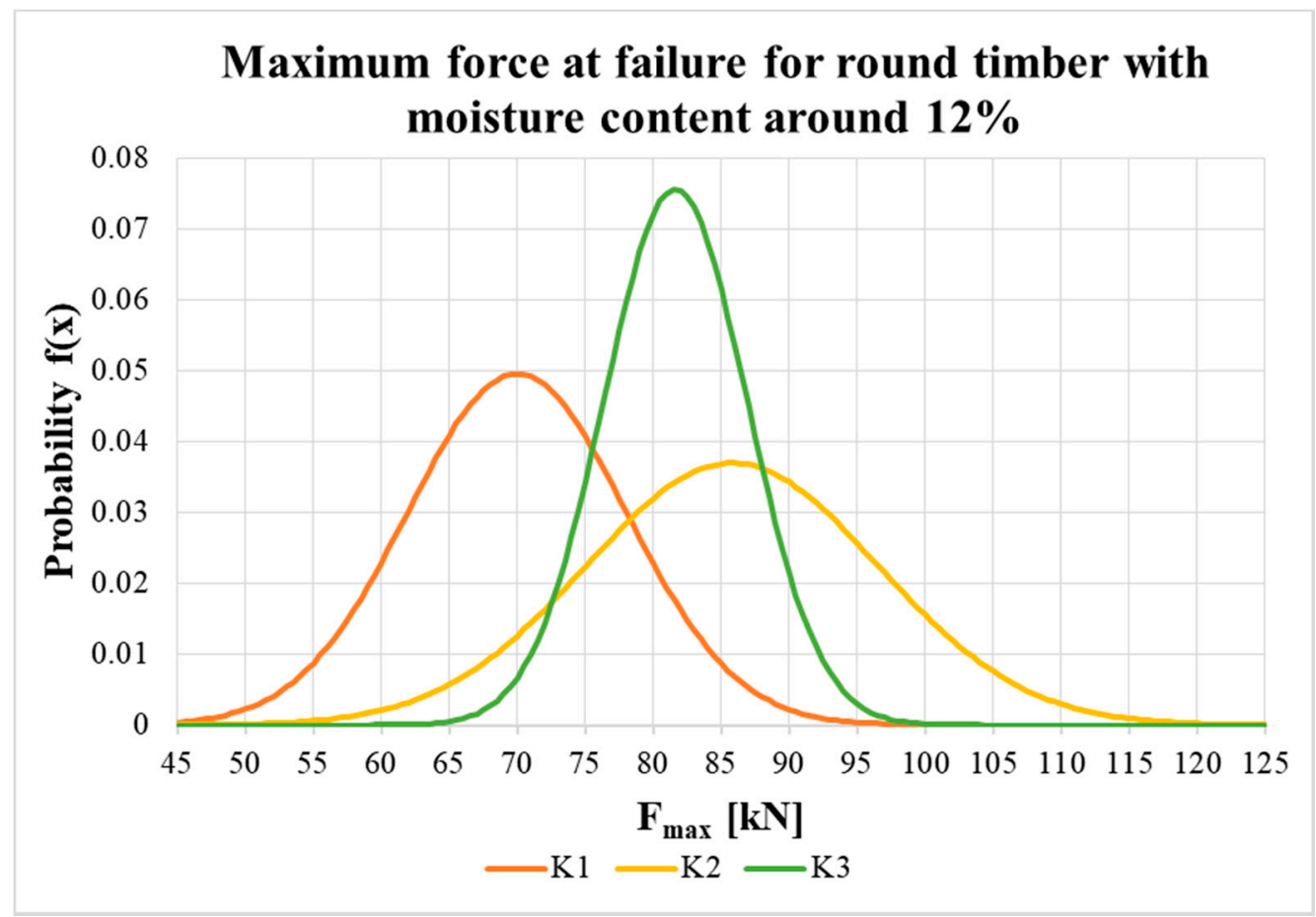

Figure 16. Probability density function of maximum force at failure for K1, K2 and K3.

Table 2 shows statistically evaluated values of bulk density and moisture content for the timber material (the values given are for timber specimens during their manufacturing), the average maximum load-carrying capacity with standard deviation, the coefficient of variation and characteristic value based on testing, the calculated characteristic load-carrying capacity without contribution from the rope effect according to Eurocode 5 [27] (see the calculation below) and the values of the initial slip modulus and the slip moduli according to the above-mentioned formulas for all types (H1, H2, H3, K1, K2 and K3). The results were not normalized for the density data due to low variability in density. A normal distribution of test values was assumed in the statistical evaluation in accordance with $[42,43]$.

Table 2. Values of bulk density, moisture content, maximum force, characteristic force and slip moduli for all types of specimens.

\begin{tabular}{ccccccc}
\hline Comparison & H1 & H2 & H3 & K1 & K2 & K3 \\
\hline$\rho(\mathrm{AVG})\left[\mathrm{kg} / \mathrm{m}^{3}\right]$ & 417 & 411 & 414 & 458 & 455 & 431 \\
$\rho(\mathrm{SD})\left[\mathrm{kg} / \mathrm{m}^{3}\right]$ & 13.4 & 20.0 & 20.6 & 34.7 & 45.1 & 34.3 \\
$\rho(\mathrm{COV})[\%]$ & 3.2 & 4.9 & 5.0 & 7.8 & 9.9 & 8.1 \\
w $(\mathrm{AVG})[\%]$ & 12.8 & 12.6 & 13.0 & 13.2 & 12.8 & 12.8 \\
w $(\mathrm{SD})[\%]$ & 0.2 & 0.6 & 0.8 & 0.6 & 0.7 & 0.4 \\
$F_{\text {max,test }}(\mathrm{AVG})[\mathrm{kN}]$ & 66.10 & 75.43 & 72.63 & 69.98 & 85.81 & 81.62 \\
$F_{\text {max,test }}(\mathrm{SD})[\mathrm{kN}]$ & 3.94 & 8.26 & 4.84 & 8.04 & 10.79 & 5.28 \\
$F_{\text {max,test }}(\mathrm{COV})[\%]$ & 6.0 & 11.0 & 6.7 & 11.5 & 12.5 & 6.5 \\
$F_{\mathrm{k}, \text { test }}[\mathrm{kN}]$ & 56.41 & 55.10 & 60.72 & 50.20 & 59.39 & 68.65 \\
$F_{\mathrm{k}, \mathrm{EC} 5}[\mathrm{kN}]$ & \multicolumn{7}{c}{46.53} & & & \\
$k_{\mathrm{i}}(\mathrm{AVG})[\mathrm{kN} / \mathrm{mm}]$ & 5852 & 5931 & 5530 & 5889 & 5804 & 5519 \\
$k_{\mathrm{s}}(\mathrm{AVG})[\mathrm{kN} / \mathrm{mm}]$ & 6817 & 5644 & 6446 & 11,298 & 11,342 & 11,129 \\
\hline
\end{tabular}


here,

$\rho$ is the bulk density of timber specimens;

$w$ is the moisture content of timber specimens;

$F_{\text {max,test }}$ is the maximum force at failure based on test data (average value and standard deviation);

$F_{\mathrm{k}, \text { test }}$ is the characteristic force at failure based on test data (determined according to [42,43]);

$F_{\mathrm{k}, \mathrm{EC} 5}$ is the characteristic load-carrying capacity according to the standard [27];

$k_{\mathrm{i}}$ is the initial slip modulus of connections based on test data;

$k_{\mathrm{s}}$ is the slip modulus of connections based on test data.

In accordance with Eurocode 5 [27], a double shear steel-to-timber connection was considered (steel plate of any thickness as the central member). The characteristic value of the load-carrying capacity, without the contribution from the rope effect for the given type of connection, according to the above-mentioned standard is $F_{v, R k}=46,528 \mathrm{~N}$ (twice 23,264 N). In order to calculate the load-carrying capacity, the necessary input values for $\mathrm{C} 24$ strength timber (determined on the basis of the standard [42]) and M20 grade 8.8 bolts were used. The calculation according to Eurocode 5 is given below in Table 3, where the failure mode $b$ is decisive.

Table 3. Calculation of characteristic load-carrying capacity according to Eurocode 5.

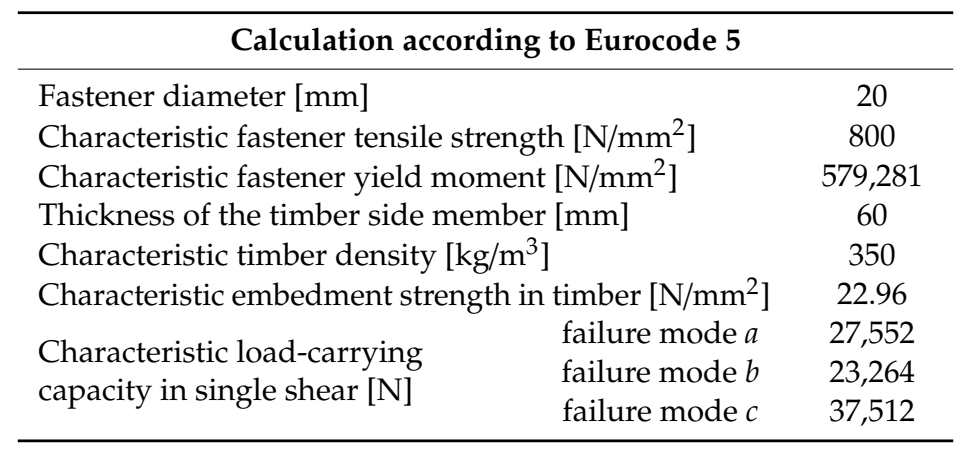

To obtain the design values, it is necessary to recalculate the characteristic value using the modified factor for the duration of load and moisture content $k_{\text {mod }}\left(k_{\text {mod }}=1.1\right.$ for the $1 \mathrm{st} / 2$ nd service class and $k_{\text {mod }}=0.9$ for the 3 rd service class, both for instantaneous load duration) and the partial factor for the material properties $\gamma_{M}\left(\gamma_{M}=1.3\right.$ for connections).

The effect of moisture content on the real load-carrying capacity of the connection is shown in Figures 17-19. The obtained data are complemented with regression line equations and correlation coefficients. The graphs are also complemented with the characteristic load-carrying capacity $F_{k}$ and design load-carrying capacities for 1st/2nd service class $F_{d} S C 1 / S C 2$ (design values for both classes were the same) and 3rd service class $F_{d} S C 3$ for instantaneous load duration based on calculation according to the standard (see the calculation below). 


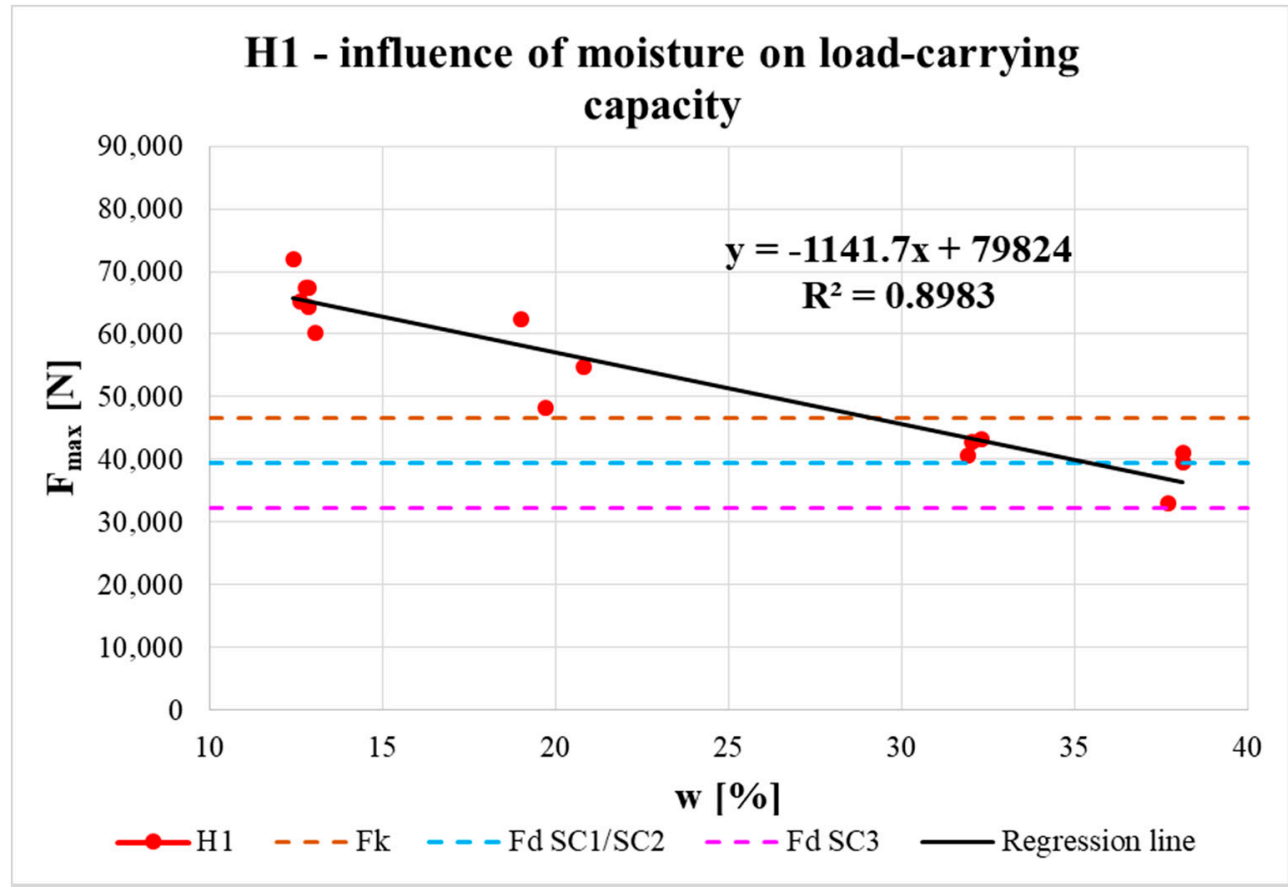

Figure 17. Influence of moisture content on load-carrying capacity of $\mathrm{H} 1$ specimens.

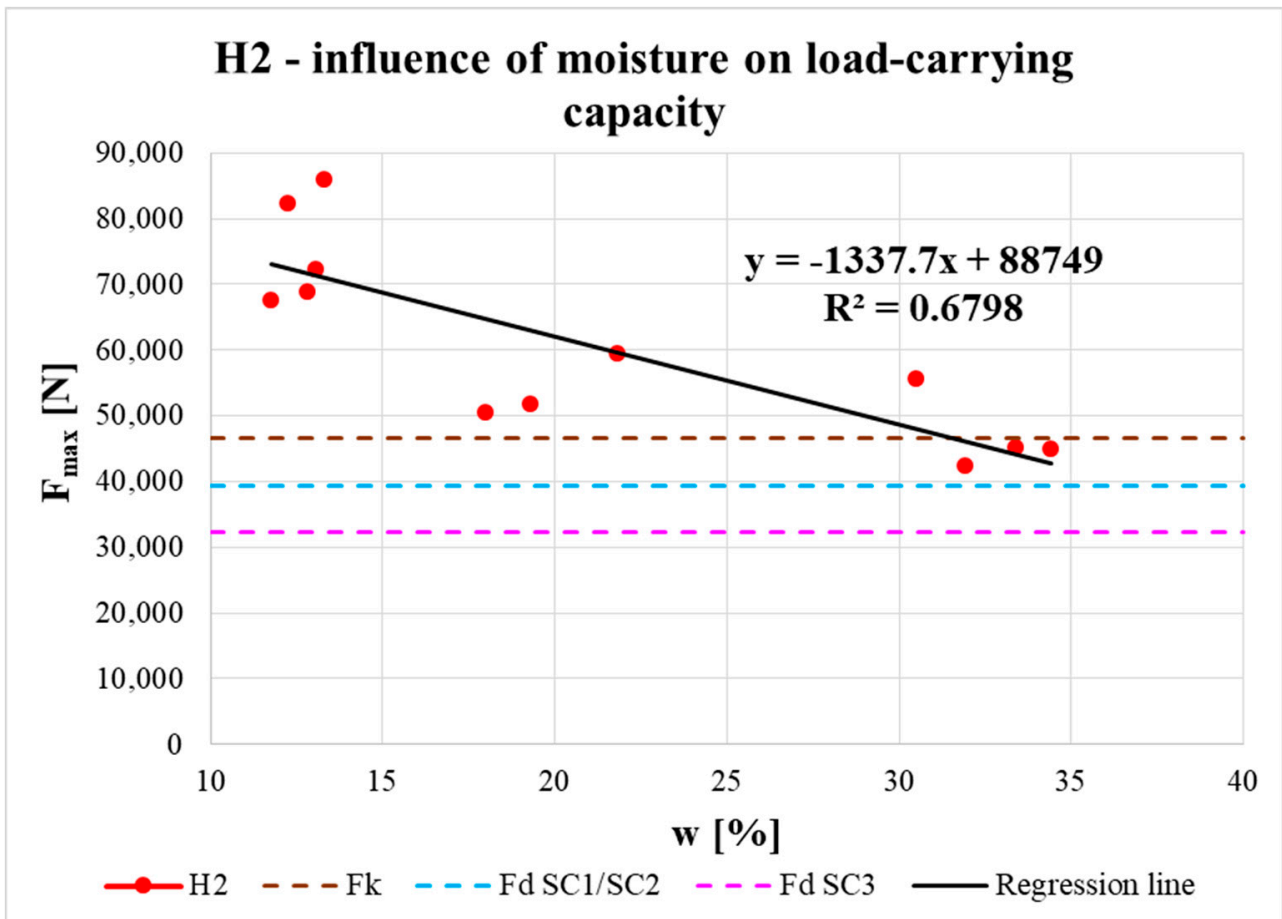

Figure 18. Influence of moisture content on load-carrying capacity of $\mathrm{H} 2$ specimens. 


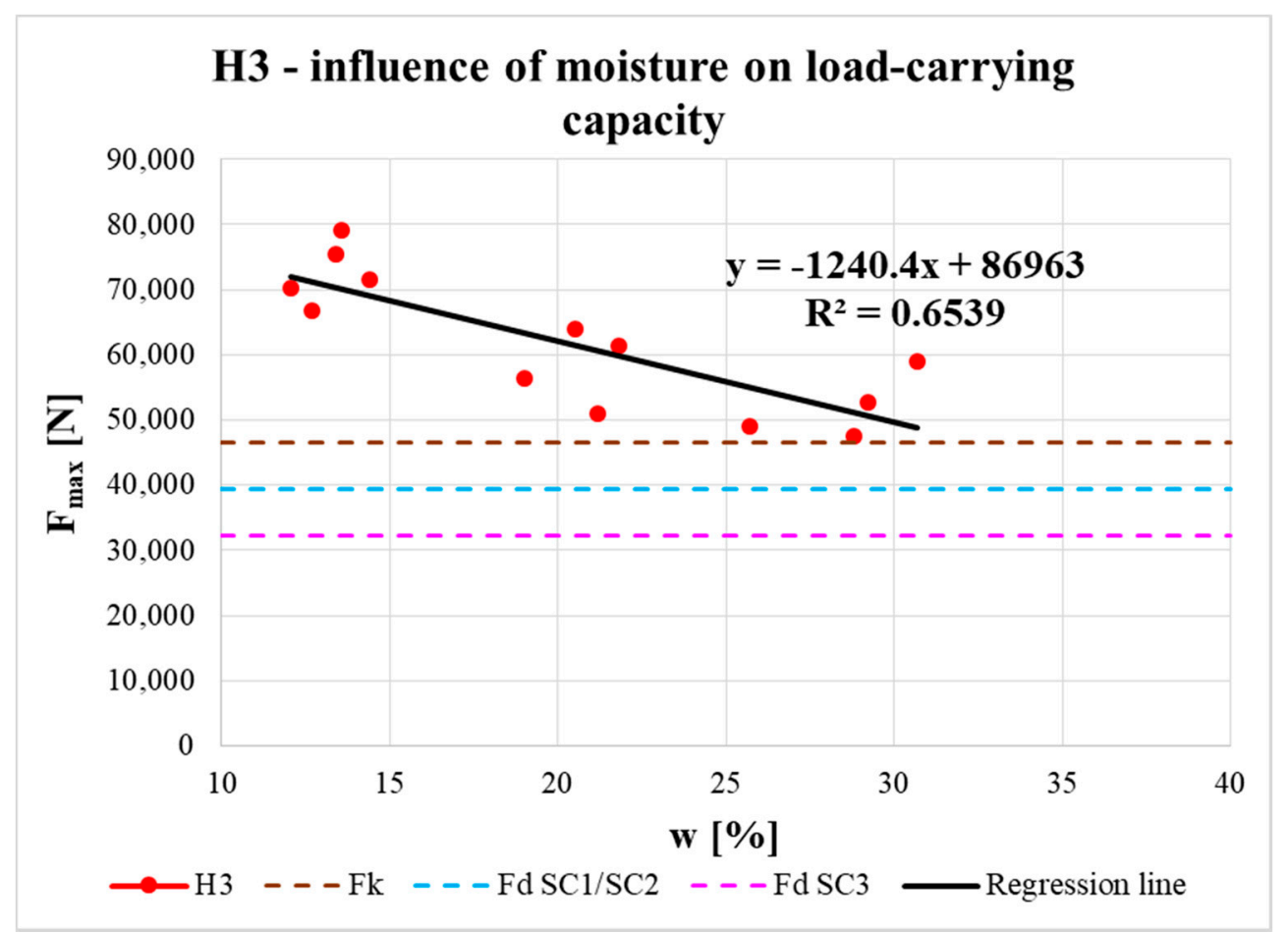

Figure 19. Influence of moisture content on load-carrying capacity of $\mathrm{H} 3$ specimens.

Figure 20 shows the load-carrying capacities of all three types of connections in squared timber at different moisture content levels, which were obtained by putting those levels into the regression line from Figures 17-19.

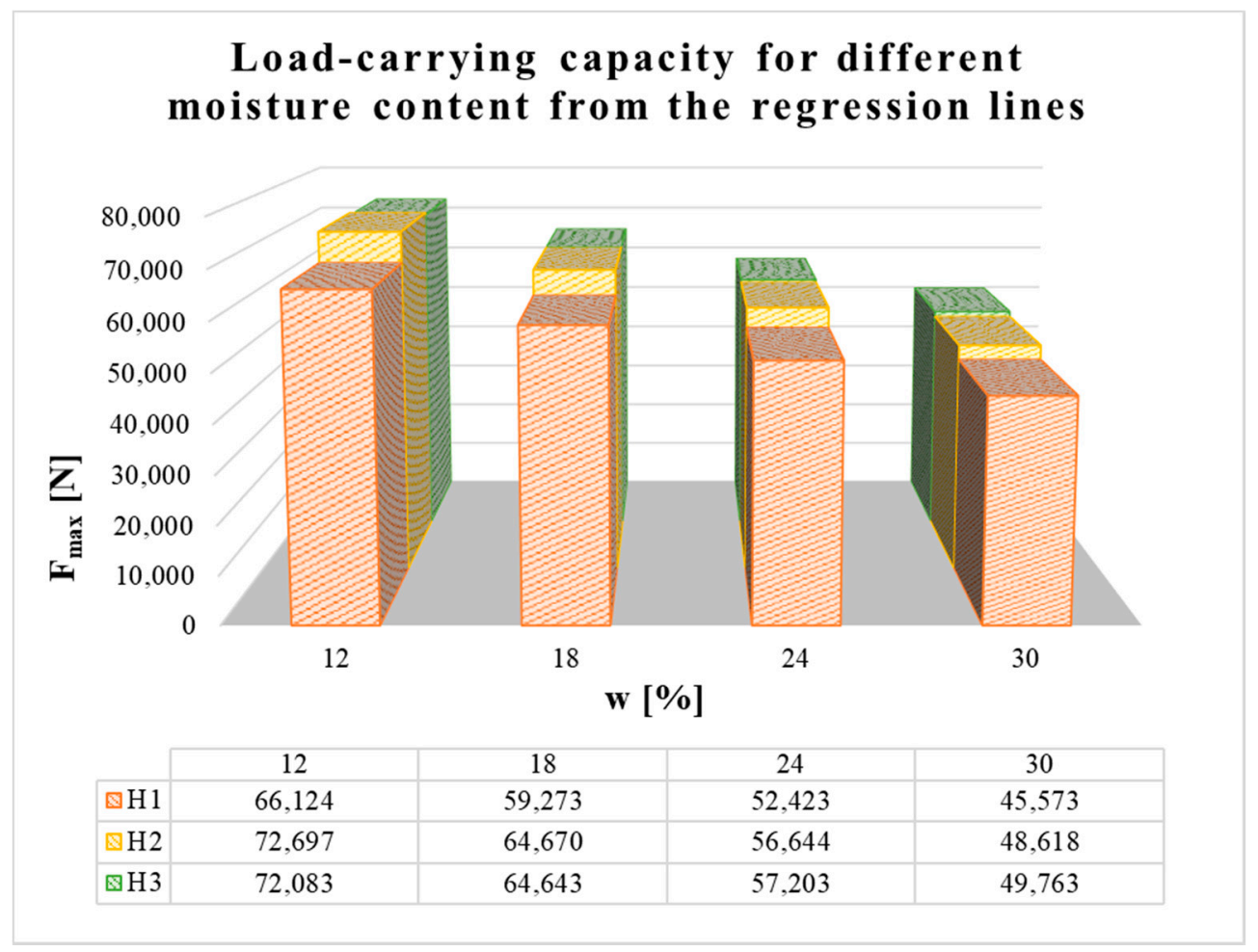

Figure 20. Load-carrying capacity for different moisture content from the regression lines. 


\section{Discussion}

From the initial loading, deformation of holes in timber members occurred until the specimens failed due to tension perpendicular to the grain. Failure always occurred by timber splitting under the bolt, when the tensile strength perpendicular to the grain was exceeded and cross-links between individual fibers in timber were broken (see Figure 8). This phenomenon can be attributed to the fact that timber under tension has little plasticity and is broken by brittle fractures. The failure in most specimens occurred after a visible embedment (ductile failure usually preceded brittle failure). The splitting crack spread very quickly in one half of a timber specimen (the other half remained only embedded) under one of the bolts and in some cases also between the bolts. Brittle failure indicated that higher capacities could be obtained and were not limited to the ductile failure modes from Eurocode 5 (depending on the embedment strength of the timber and yield moment of the fastener, see Section 3).

The maximum force values at specimen failure with moisture content around $12 \%$ (see Table 2) showed that, at the shortest distance between the fastener and loaded end (i.e., $7 d$ ), the average values were lowest for both the squared timber and round timber. For specimens with longer distances (i.e., $9 d$ and $11 d$ ), the average load-carrying capacity was higher, and the highest value was surprisingly for middle-length specimens (H2 and K2 specimens). Higher load-carrying capacities were measured for round timber specimens than for squared specimens, probably due to the higher average bulk density of the timber (higher by between $4.1 \%$ and $11.8 \%$ ). The results also show that there was no increase in real load-carrying capacity above the end distance $9 d$, so the use of a higher end distance has no practical significance.

However, in construction, useful values are so called characteristic values, evaluated as the $5 \%$ quantile of the approximated probability distribution of the measured values. Characteristic values are significantly influenced by the number of specimens (reduction in the number of test specimens, $k_{s}(n)$, according to [43]) and variability in the measured values (sample standard deviation). The characteristic load-carrying capacities for all types of specimens were higher than the standard value for the double shear steel-to-timber connection (steel plate of any thickness as the central member). The highest values were found for $\mathrm{H} 3$ and $\mathrm{K} 3$ specimens (the longest distance of the bolt from the loaded end); for $\mathrm{H} 3$ specimens it was higher by $30.5 \%$ and for $\mathrm{K} 3$ specimens it was higher by $47.5 \%$. Nevertheless, it is not possible to conclude there was a significant influence exerted by the distance between the fastener and the loaded end on the characteristic load-carrying capacity of the connection. This is complicated by the small number of tested specimens, which considerably affects the statistical evaluation of specimens with higher variance (especially specimens with coefficients of variation higher than $10 \%)$.

In addition, considerable variability can be seen in the slip moduli (see Table 2). The slip modulus $k_{s}$ was higher for round timber than for squared timber (almost twice as high), which is probably, again, due to the higher bulk density of round timber.

It is known that with increasing moisture content in timber elements (related to service class assignment), the load-carrying capacity of elements, and their connections, is reduced by the modification factor $k_{\text {mod }}$. This decrease in real load-carrying capacity with increasing moisture content was also confirmed experimentally. The measured data could be approximated by a straight line using regression analysis (see Figures 17-19). Correlation coefficients were evaluated ( $\mathrm{R}=-0.95$ for $\mathrm{H1}$ specimens, $\mathrm{R}=-0.82$ for $\mathrm{H} 2$ specimens, $\mathrm{R}=-0.81$ for $\mathrm{H} 3$ specimens) and they indicated significant correlation between the examined parameters. The slopes of all the regression lines were quite similar, which indicates a similar effect of moisture content on load-carrying capacity for all types of specimens. The small differences were mainly due to the end distances.

Regression lines were then used to determine the load-carrying capacities for different moisture contents. The results show that at the shortest distance between the fastener and loaded end (i.e., $7 d$ ) the load-carrying capacity was lowest. For specimens with longer distances (i.e., $9 d$ and 11d), the average load-carrying capacities were higher and the values for both distances were almost comparable. It can therefore be observed that with increasing distance between the fastener and the loaded end, there was 
a slight increase in the real load-carrying capacity (from the minimum standard value of $7 d$ to the value of $9 d$ ). As the distance increased further, the increase in load-carrying capacity was practically negligible (from $9 d$ to $11 d$ ).

To assign the structure to service class 1 , the moisture content of the built-in timber elements needs to be around the equilibrium moisture content of $12 \%$ (only for interiors). To assign the structure to service class 2 , this moisture content must not exceed $20 \%$. In cases where the moisture content is more than $20 \%$, it is necessary to assign the structure to service class 3 [27]. Figures 17-19 show that for all types of specimens with moisture contents around 12\% (corresponding to service class 1) and $20 \%$ (corresponding to service class 2 ), the real load-carrying capacities were higher than the design value for service classes 1 or 2, even higher than the characteristic value according to the standard [27]. Furthermore, for specimens with the highest moisture content (corresponding to service class 3 ), the real load-carrying capacities were higher than the design value for service class 3 according to the standard [27]. For $\mathrm{H} 2$ specimens, the real load-carrying capacities were higher than the design value for service classes 1 or 2 and for $\mathrm{H} 3$ specimens they were even higher than the characteristic value. The values of real load-carrying capacities for $\mathrm{H} 1$ specimens with the highest moisture content point to the importance of carefully designing timber structures, especially exterior details (connections), because of the significant influence from atmospheric conditions, which can lead to rainwater flowing into improperly designed details and, subsequently, significantly decrease the real load-capacity capacity to the limit according to the standard [27].

With increasing moisture content in the squared timber specimens, a slight increase in the slip modulus can be observed, which appears to be due to the swelling of timber when it is saturated with water. However, no significant correlation was found between the slip modulus and moisture content dependence.

According to Figures 10 and 11, specimens $\mathrm{H} 2$ and $\mathrm{H} 3$ also showed higher ductility in the final phase of loading before total brittle failure compared to specimen H1.

\section{Conclusions}

Experimental testing is the most appropriate way to verify the load-carrying capacity and stiffness of timber structures. Therefore, tests on bolted connections in squared and round timber with inserted steel plates, with different distances between the fastener and the loaded end, were performed.

Connections with inserted steel plates are also widely used in exterior timber structures (e.g., lookout towers [1], bridges [2], etc.) that are exposed to significant temperature and moisture content changes. Therefore, the effect of increased moisture content in timber on the load-carrying capacity of the connections was also analyzed in the experiment.

The following partial conclusions can be drawn:

- Connection failure always occurred by timber splitting under the bolt, when the tensile strength perpendicular to the grain was exceeded.

- The average load-carrying capacity was lowest for the shortest fastener distance for both the squared timber and round timber. For specimens with higher distances, the average load-carrying capacity was higher.

- Considerable variability in the slip modulus can be seen in the evaluation. The slip modulus is higher for the round timber than for the squared timber, which is probably due to the higher bulk density of round timber.

- The decrease in real load-carrying capacity with increasing moisture content was also confirmed experimentally. The measured data could be approximated by a straight line using regression analysis.

The limitations of this research include the use of only one fastener in a row (bolt M12 8.8) and only one species of timber (spruce, C24 strength class), the limited number of test specimens (which affects the statistical evaluation) and the monotonic static testing. 
Exterior structures are also predominantly loaded by wind, which has the characteristics of an alternating dynamic load [46]. On the basis of these facts, future research on this issue should incorporate experiments with cyclic and dynamic tests $[8,47]$.

Author Contributions: Conceptualization, P.D. and A.L.; Data curation, P.D.; Formal analysis, P.D.; Funding acquisition, P.D.; Investigation, P.D. and A.L.; Methodology, P.D., O.S. and A.L.; Supervision, A.L.; Validation, P.D. and A.L.; Visualization, O.S.; Writing-original draft, P.D. All authors have read and agreed to the published version of the manuscript.

Funding: This paper was financially supported by the Ministry of Education, specifically by the Student Research Grant Competition of the Technical University of Ostrava in 2020 under identification number SP2020/138.

Conflicts of Interest: The authors confirm that there are no known conflict of interest associated with this paper.

\section{References}

1. Šmak, M.; Barnat, J.; Straka, B.; Kotásková, P.; Havírová, Z. Dowelled joints in timber structures experiment-design-realization. Wood Res. 2016, 61, 651-662.

2. Fojtik, R.; Lokaj, A.; Gabriel, J. Wooden Bridges and Footbridges; Czech Chamber of Authorized Engineers and Technicians in Construction (CKAIT): Prague, Czech Republic, 2017; p. 158. ISBN 978-80-88265-04-7.

3. Bergman, R.; Puettmann, M.; Taylor, A.; Skog, K.E. The carbon impacts of wood products. For. Prod. J. 2014, 64, 220-231. [CrossRef]

4. Blass, H.J.; Sandhaas, C. Timber Engineering-Principles for Design; Karlsruher Institut für Technologie: Karlsruhe, Czech Republic, 2017; ISBN 978-3-7315-0673-7.

5. Borgström, E.; Karlsson, R. Design of Timber Engineering-1; Swedish Wood: Stockholm, Sweden, 2016.

6. Sandhaas, C.; Munch-Andersen, J.; Dietsch, P. Design of Connections in Timber Structures; Shaker-Verlag GmbH: Düren, Germany, 2018; ISBN 978-3-8440-6144-4.

7. Que, Z.; Hou, T.; Gao, Y.; Teng, Q.; Chen, Q.; Wang, C.; Chang, C. Influence of Different Connection Types on Mechanical Behavior of Girder Trusses. J. Bioresour. Bioprod. 2019, 4, 89-98.

8. Lokaj, A.; Klajmonova, K. Carrying capacity of round timber bolted joints with steel plates under cyclic loading. Adv. Mater. Res. 2013, 838-841, 634-638. [CrossRef]

9. Lokaj, A.; Klajmonova, K. Round timber bolted joints exposed to static and dynamic loading. Wood Res. 2014, $59,439-448$.

10. Lokaj, A.; Klajmonova, K.; Mikolasek, D.; Vavrusova, K. Behavior of round timber bolted joints under tension load. Wood Res. 2016, 61, 819-830.

11. Lokaj, A.; Klajmonova, K. Comparison of behaviour of laterally loaded round and squared timber bolted joints. Frat. ed Integrita Strutt. 2017, 11, 56-61. [CrossRef]

12. Lokaj, A.; Klajmonova, K. Round timber bolted joints reinforced with self-drilling screws. Procedia Eng. 2015, 114, 263-270.

13. Kiwelu, H.M. Experimental study on the effect of moisture on bolt embedment and connection loaded parallel to grain for timber structures. Tanzan. J. Eng. Technol. 2019, 38, 47-59.

14. Blass, H.J.; Schädle, P. Ductility aspects of reinforced and non-reinforced joints. Eng. Struct. 2011, 33, 3018-3026. [CrossRef]

15. Sandhaas, C. Mechanical Behaviour of Timber Joints with Slotted-in Steel Plates. Ph.D. Thesis, TU Delft, Delft, The Netherlands, 2012.

16. Cabrero, J.M.; Yurita, M.; Quenneville, P. Brittle failure in the parallel-to-grain direction of multiple shear softwood timber connections with slotted-in steel plates and dowel-type fasteners. Constr. Build. Mater. 2019, 216, 296-313.

17. Sawata, K. Strength of bolted timber joints subjected to lateral force. J. Wood Sci. 2015, 61, 221-229. [CrossRef]

18. Glisovic, I.; Stevanovic, B.; Kocetov-Misulic, T. Embedment test of wood for dowel-type fasteners. Wood Res. 2012, 57, 639-650.

19. Jockwer, R.; Fink, G.; Kohler, J. Assessment of the failure behaviour and reliability of timber connections with multiple dowel-type fasteners. Eng. Struct. 2018, 172, 76-84. [CrossRef]

20. Rahim, N.L.; Raftery, G.M.; Quenneville, P. Stiffness of bolted timber connection. In Proceedings of the World Conference on Timber Engineering, Seoul, Korea, 20-23 August 2018. 
21. Awaludin, A.; Saputro, D.N. Bolt spacing and end distance of bolted connection of laminated veneer lumber (LVL) sengon. Civ. Eng. Dimens. 2017, 19, 1-6.

22. Salenikovich, A.; Legras, B.; Mohammad, M.; Quenneville, P. Effect of moisture on the performance of bolted connections in timber structures. In Proceedings of the 11th Conference on Timber Engineering, Trentino, Italy, 20-24 June 2010; Volume 2, pp. 960-969.

23. Carll, C. Moisture durability for wood products. VTT Symp. 2010, 263, 142-147.

24. Roszyk, E.; Stachowska, E.; Majka, J.; Mania, P.; Broda, M. Moisture-dependent strength properties of thermally-modified fraxinus excelsior wood in compression. Materials 2020, 13, 1647. [CrossRef]

25. Sjödin, J.; Johansson, C.J. Influence of initial moisture induced stresses in multiple steel-to-timber dowel joints. Holz Roh Werkst. 2007, 65, 71-77. [CrossRef]

26. Rammer, D.R.; Winistorfer, S.G. Effect of moisture content on dowel-bearing strength. Wood Fiber Sci. 2001, 33, 126-139.

27. EN 1995-1-1. Eurocode 5: Design of Timber Structures-Part 1-1: General-Common Rules and Rules for Buildings; Czech Standards Institute: Praha, Czech Republic, 2006.

28. Zhu, E.; Pan, J.; Zhou, X.; Zhou, H. Experiments of load-carrying capacity of bolted connections in timber structures and determination of design value. J. Build. Struct. 2016, 37, 54-63.

29. Jorissen, A.J.M. Double Shear Timber Connections with Dowel Type Fasteners. Ph.D. Thesis, TU Delft, Delft, The Netherlands, 1998.

30. Yurrita, M.; Cabrero, J.M. New design model for splitting in timber connections with one row of fasteners loaded in the parallel-to-grain direction. Eng. Struct. 2020, 223, 111155. [CrossRef]

31. Quenneville, P.; Mohammad, M. On the failure modes and strength of steel-wood-steel bolted timber connections loaded parallel-to-grain. Can. J. Civ. Eng. 2011, 27, 761-773. [CrossRef]

32. Johansen, K.W. Theory of timber connections. Int. Assoc. Bridg. Struct. Eng. 1949, 9, 249-262.

33. Jorissen, A.J.M.; Fragiacomo, M. General notes on ductility in timber structures. Eng. Struct. 2011, 33, 2987-2997. [CrossRef]

34. Cabrero, J.M.; Yurita, M. Performance assessment of existing models to predict brittle failure modes of steel-to-timber connections loaded parallel-to-grain with dowel-type fasteners. Eng. Struct. 2018, 171, 895-910. [CrossRef]

35. Vavrusova, K.; Mikolasek, D.; Lokaj, A.; Klajmonova, K.; Sucharda, O. Determination of carrying capacity of steel-timber joints with steel rods glued-in parallel to grain. Wood Res. 2016, 61, 733-740.

36. Franke, B.; Quenneville, P. Prediction of the load capacity of dowel-type connections loaded perpendicular to grain for solid wood and wood products. In Proceedings of the World Conference on Timber Engineering, Auckland, New Zealand, 15-19 July 2012.

37. Dobes, P.; Lokaj, A.; Sucharda, O. Test results of connections of timber structures. In Proceedings of the 204th IASTEM International Conference, Amsterdam, The Netherlands, 10 September 2019; Volume 204, pp. 1-4.

38. Dobes, P.; Lokaj, A.; Sucharda, O. Load-carrying capacity of bolted connections of round timber with different distances between the fastener and the loaded end. In Proceedings of the 3rd International Conference on Sustainable Development in Civil, Urban and Transportation Engineering, Ostrava, Czech Republic, 21-23 October 2020; Volume 3, pp. 109-112.

39. Awaludin, A.; Hirai, T.; Hayashikawa, T.; Sasaki, Y. Load-carrying capacity of steel-to-timber joints with a pretensioned Bolt. J. Wood Sci. 2008, 54, 362-368. [CrossRef]

40. Chen, J.; Wang, H.; Yu, Y.; Liu, Y.; Jiang, D. Loosening of bolted connections under transverse loading in timber structures. Forests 2020, 11, 816. [CrossRef]

41. EN 73 2824-1. Strength grading of wood-Part 1: Coniferous sawn timber. In Metrology and Testing; Czech Office for Standards: Praha, Czech Republic, 2015.

42. EN 384+A1. Structural Timber-Determination of Characteristic Values of Mechanical Properties and Density; Czech Office for Standards, Metrology and Testing: Praha, Czech Republic, 2019.

43. EN 14358. Timber Structures-Calculation of Characteristic 5-Percentile Values and Acceptance Criteria for a Sample; Czech Office for Standards, Metrology and Testing: Praha, Czech Republic, 2017.

44. EN 13183-2. Moisture Content of a Piece of Sawn Timber-Part 2: Estimation by Electrical Resistance Method; Czech Office for Standards, Metrology and Testing: Praha, Czech Republic, 2002. 
45. EN 26891. Timber Structures. Joints Made with Mechanical Fasteners. General Principles for the Determination of Strength and Deformation Characteristics; Czech Office for Standards, Metrology and Testing: Praha, Czech Republic, 1994.

46. Solarino, F.; Giresini, L.; Chang, W.S.; Huang, H. Experimental Tests on a Dowel-Type Timber Connection and Validation of Numerical Models. Buildings 2017, 7, 116. [CrossRef]

47. Piazza, M.; Polastri, A.; Tomasi, R. Ductility of timber joints under static and cyclic loads. Proc. Inst. Civ. Eng.-Struct. Build. 2011, 164, 79-90. [CrossRef]

Publisher's Note: MDPI stays neutral with regard to jurisdictional claims in published maps and institutional affiliations.

(C) 2020 by the authors. Licensee MDPI, Basel, Switzerland. This article is an open access article distributed under the terms and conditions of the Creative Commons Attribution (CC BY) license (http://creativecommons.org/licenses/by/4.0/). 